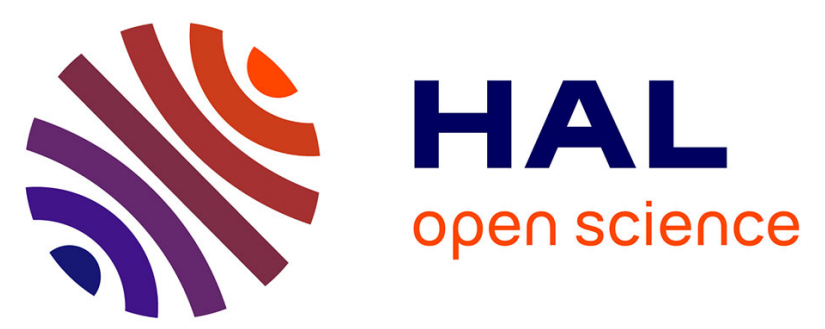

\title{
MONOLITHIC VERSUS HIERARCHICAL APPROACH TO INTEGRATED SCHEDULING IN A SUPPLY CHAIN
}

Tadeusz J. Sawik

\section{- To cite this version:}

Tadeusz J. Sawik. MONOLITHIC VERSUS HIERARCHICAL APPROACH TO INTEGRATED SCHEDULING IN A SUPPLY CHAIN. International Journal of Production Research, 2009, 47 (21), pp.5881-5910. 10.1080/00207540802193181 . hal-00513041

\section{HAL Id: hal-00513041 \\ https://hal.science/hal-00513041}

Submitted on 1 Sep 2010

HAL is a multi-disciplinary open access archive for the deposit and dissemination of scientific research documents, whether they are published or not. The documents may come from teaching and research institutions in France or abroad, or from public or private research centers.
L'archive ouverte pluridisciplinaire HAL, est destinée au dépôt et à la diffusion de documents scientifiques de niveau recherche, publiés ou non, émanant des établissements d'enseignement et de recherche français ou étrangers, des laboratoires publics ou privés. 


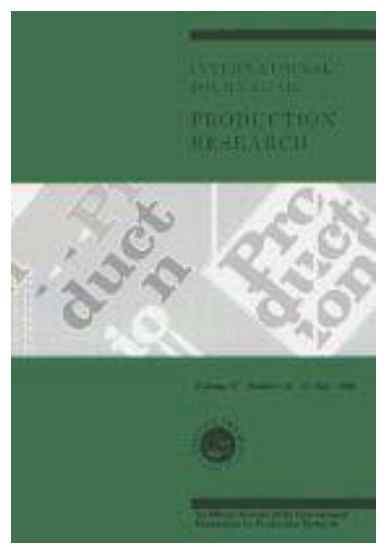

\section{MONOLITHIC VERSUS HIERARCHICAL APPROACH TO INTEGRATED SCHEDULING IN A SUPPLY CHAIN}

\begin{tabular}{|r|l|}
\hline Journal: & International Journal of Production Research \\
\hline Manuscript ID: & TPRS-2008-IJPR-0088.R1 \\
\hline Manuscript Type: & Original Manuscript \\
\hline $\begin{array}{r}\text { Date Submitted by the } \\
\text { Author: }\end{array}$ & 03-May-2008 \\
\hline Complete List of Authors: & $\begin{array}{l}\text { Sawik, Tadeusz; AGH University of Science and Technology, Dept of } \\
\text { Operations Research and Information Technology }\end{array}$ \\
\hline Keywords: & $\begin{array}{l}\text { SUPPLY CHAIN MANAGEMENT, SCHEDULING, MULTI-CRITERIA } \\
\text { DECISION MAKING, INTEGER PROGRAMMING }\end{array}$ \\
\hline Keywords (user): & Supply chain operations, Production and supply scheduling \\
\hline
\end{tabular}

\section{๑) ScholarONE" Manuscript Central}




\title{
MONOLITHIC VERSUS HIERARCHICAL APPROACH TO INTEGRATED SCHEDULING IN A SUPPLY CHAIN
}

\author{
Tadeusz Sawik \\ AGH University of Science \& Technology \\ Department of Operations Research and Information Technology \\ Al.Mickiewicza 30, 30-059 Kraków, POLAND \\ tel.: +48126173992 \\ e-mail: ghsawik@cyf-kr.edu.pl
}

\begin{abstract}
:
The two approaches, monolithic and hierarchical, with a set of mixed integer programming formulations are proposed and compared for multi-objective integrated scheduling in a customer driven supply chain. The supply chain consists of multiple manufacturers (suppliers) of parts, a single producer of finished products and a set of customers which generates final demand for the products. Each supplier has a number of identical production lines in parallel for manufacturing of parts, and the producer has a flexible assembly line for assembly of products. Given a set of orders, the problem objective is to determine which orders are to be provided with parts by each supplier, find a schedule for manufacturing of parts at each supplier and for delivery the parts from each supplier to the producer, and find a schedule for an assembly of products for each order by the producer, such that a certain performance measure of the supply chain is optimized. The selection of parts supplier for each order is combined with due date setting for some orders, subject to available capacity of the suppliers and the producer. Different objective functions are considered which take into account both the customer service level and the total manufacturing, delivery and production cost. Numerical examples modeled after a real-world integrated scheduling in a customer driven supply chain of high-tech products are presented and some computational results are reported to compare the two approaches.
\end{abstract}

\section{Keywords:}

Supply chain operations, Production and supply scheduling, Supplier selection, Due dates setting, Multi-objective optimization, Integer programming. 


\section{Introduction}

Coordination of raw materials manufacturing and supply, and finished goods production and distribution is one of the main issues of supply chain management, in particular, in customer driven supply chains, e.g., Thomas and Griffin (1996), Erenguc et al.(1999), Kolisch (2000), Shapiro (2001), Schneeweiss and Zimmer (2004), Chen and Vairaktarakis (2005), Chen and Pundoor (2006), Chen and Hall (2007), Kaczmarczyk et al. (2006).

Most existing supply-production-distribution models study strategic or tactical levels of production-distribution decisions (see, Chen, 2004) and very few have addressed integrated decisions of supply-production stages of a supply chain, at the detailed scheduling level.

The majority of research on supply chain coordination is devoted to developing joint economic lot size models, where the objective is to determine joint economic ordering and production lot sizes to simultaneously minimize total cost of material ordering and holding and manufacturing setup and finished products holding, e.g. Goyal and Deshmukh (1992), Lee (2005). However, the models are based on various simplifying assumptions such as a single finished product with a constant or a piece-wise linear demand pattern. Therefore, the models cannot be directly applied in a complex, multi-product make-to-order environment, with an arbitrary demand pattern for different finished products. A coordination between the procurement and production policies in a just-in-time environment is proposed by Goyal and Deshmukh (1997). Their model, again restricted to a single product, aims at the minimization of total variable cost and determining the lot sizes for the product and raw material order sizes in a multi stage batch environment.

A typical customer driven supply chain may consist of a number of part manufacturers at several locations (e.g. countries) and a single producer (e.g. a distribution center), where parts are supplied by the manufacturers and assembled into finished products distributed to customers. In such a supply chain, productivity may vary from plant to plant and transportation time and cost are not negligible. Due to a limited capacity of both the part manufacturers and the producer, available to complete customer orders by the customer required shipping dates, the manufacturing and supply schedules for each supplier of parts and the assembly schedule for finished products should be coordinated in an efficient manner to achieve a high customer service level at a low cost.

Simplified models for integrated scheduling of production and distribution operations are studied by Chen and Vairaktarakis (2005) and Chen and Pundoor (2006), where transportation time and cost are considered. The authors have analyzed computational complexity of various cases of the problem and have developed heuristics for NP-hard cases. Hall and Potts (2003) consider a different set of models that treats both delivery lead time and transportation 
cost, but assume that delivery is done instantaneously without any transportation time, and Hall et al. (2001) investigate another model with a fixed set of possible delivery dates. The issues of conflict and cooperation between the suppliers and the manufacturer are studied by Chen and Hall (2007), where classical scheduling objectives are considered: minimization of the total completion time and of the maximum lateness. Moon et al. (2007) propose the evolutionary search approach to find feasible solutions for a simplified integrated process planning and scheduling in a supply chain and Chauhan et al. (2007) consider a real-time scheduling of flow-shops with the no-wait constraint in supply chain environment.

The supply chain considered in this paper consists of multiple manufacturers (suppliers) of parts, a single producer of finished products and a set of customers which generates final demand for the products. Each supplier has a number of identical production lines in parallel for manufacturing of parts, and the producer has a flexible assembly line for assembly of products. In the supply chain, the following static and deterministic integrated scheduling problem is considered. Given a set of orders, the problem objective is to determine which orders are to be provided with parts by each supplier, find a schedule for manufacturing of parts at each supplier and for delivery the parts from each supplier to the producer, and find a schedule for an assembly of products for each order by the producer, such that a high customer service level is achieved and the total cost of supply chain inventory holding, the production line start-ups and the part shipments is minimized. The selection of part supplier for each customer order is combined with a due date setting for some orders to maximize the number of orders that can be completed by customer requested due dates.

In the literature on production planning and scheduling the integer programming models have been widely used, e.g. Shapiro (2001), Pochet and Wolsey (2006). For example, a mixed integer programming formulation for the integrated assembly scheduling and fabrication lot sizing in make-to order production is proposed in Kolisch (2000), with the objective function that minimizes the total inventory holding and fabrication setup cost. Operational, noncentralized coordination mechanism between a producer and a supplier within a supply chain, based on the theory of hierarchical planning and mixed integer programming is presented in Schneeweiss and Zimmer (2004). A mixed integer programming formulation for the optimal scheduling of industrial supply chains is presented by Amaro and Barbosa-Póvoa (2007). The lexicographic approaches with a hierarchy of integer programming formulations for a multiobjective, long-term production scheduling in make-to-order manufacturing are proposed by Sawik (2007b, 2007c), where both maximization of the customer satisfaction and leveling of production and inventory are integrated in the objective functions.

The major contribution of this paper is that it compares a monolithic and a hierarchical 
approach (cf. Sawik, 2002) to the multi-objective, coordinated supply chain scheduling. This paper proposes a decomposition of the complex problem of multi-objective production, manufacturing and supply scheduling into a hierarchy of much simpler decision-making problems and for their solution provides simple integer programming formulations. The objective functions integrate both the supply chain performance and the customer service level and in the problem considered the scheduling is combined with a selection of part supplier for each customer order and a due date setting for some orders.

The paper is organized as follows. In the next section description of the integrated scheduling problem in a customer driven supply chain is provided. The conditions for feasibility of customer requested due dates are derived in Section 3. The monolithic model for the multiobjective integrated scheduling is proposed in Section 4, and the hierarchical approach with a set of integer programming formulations is presented in Section 5. Numerical examples modeled after a real-world customer driven supply chain and some computational results are provided in Section 6. Conclusions are made in the last section.

\section{Problem description}

Figure 1. Customer driven supply chain.

The supply chain under consideration (Fig. 1) consists of $m$ manufacturers/suppliers of product-specific parts, a single producer where finished products are assembled according to customer orders and a set of customers which generates final demand for the products. In the supply chain various types of products are assembled by the producer using different productspecific part types supplied by the manufacturers. Let $J$ be the set of customer orders known ahead of time, $K$ - the set of part types, $L$ - the set of product types, and $J_{l}$ - the subset of orders for product type $l \in L$. Each product type $l \in L$ requires $b_{k l} \geq 0$ parts of type $k \in K$.

Each order $j \in J$ is described by a triple $\left(a_{j}, d_{j}, o_{j}\right)$, where $a_{j}$ is the order ready date (e.g. the earliest period of material availability), $d_{j}$ is the customer requested due date (e.g. customer required shipping date), and $o_{j}$ is the size of order (quantity of ordered products of a specific type).

The planning horizon consists of $h$ planning periods (e.g. working days) of equal length $H$ (e.g. hours or minutes) and let $T=\{1, \ldots h\}$ be the set of planning periods. It is assumed that each customer order must be fully completed in exactly one planning period (e.g. during one day), however, this assumption can be easily relaxed. Large size orders that require 
more than one planning period for completion can be split into single-period suborders to be allocated among consecutive planning periods, see Section 4.4 (e.g. Sawik, 2007b).

The suppliers manufacture and deliver product-specific parts to the producer. The manufacture of parts by supplier $i \in I$, at the earliest can be started $e_{i}$ periods in advance of period $t=1$, when the producer can start the assembly of products. The earliness $e_{i}$ of manufacturing start time for supplier $i$ represents the maximum manufacturing capacity of supplier $i$ available in advance of the start of assembly schedule. Each supplier $i$ has $M_{i}$ identical production lines in parallel, capable of manufacturing all part types and let $q_{i k}$ be the processing time for part type $k \in K$ at supplier $i$. In each period at most one part type can be manufactured on each production line. When a production line switches from one part type to another, a start-up time should be considered at the beginning of the period. The start-up times are sequence-independent and are assumed to be equal for all part types. Let $\sigma_{i}$ be the start-up time of each production line of supplier $i$.

The manufactured parts are next transported to the producer at most once per period. Different part types can be shipped together so that a shipping cost arises only once per shipment. Each delivery shipment is limited by the minimum and the maximum capacity, respectively $\underline{V}$ and $\bar{V}$ parts. The transportation time of a shipment from supplier $i$ to the producer is assumed to be constant and equals to $\theta_{i}$ periods. The parts manufactured by supplier $i$ in period $t$ can be shipped to the producer in the same period and can be used for the assembly of products in period $t+\theta_{i}$, at the earliest.

The producer has a flexible assembly line that consists of $f$ assembly stages in series and each stage $g \in G=\{1, \ldots, f\}$ is made up of $m_{g} \geq 1$ identical, parallel machines. Each customer order requires processing in various assembly stages, however some orders may bypass some stages. Let $p_{g j} \geq 0$ be the processing time in stage $g$ of each product in order $j$, and $o_{j} p_{g j}$ is the total processing time required to complete order $j$ in stage $g$.

Table 1. Notation: indices and parameters

The problem objective is to determine which orders are to be provided with parts by each supplier, find a schedule for manufacturing of parts at each supplier and for delivery the parts from each supplier to the producer, and find a schedule for an assembly of products for each order by the producer, such that a high customer service level is achieved and the total cost of supply chain inventory holding, the production line start-ups and the part shipments is minimized. The selection of part supplier for each customer order is combined with a due date setting for some orders to maximize the number of orders that can be completed by customer requested due dates. 
A monolithic approach, where manufacturing, supply and assembly schedules are determined simultaneously is compared with a hierarchical approach. In the proposed hierarchical approach, first a supplier of parts is selected for each order, the maximal subset of orders that can be completed by the customer requested due dates is found and for the remaining orders delayed due dates are determined to satisfy capacity constraints. Then, the assignment of orders to planning periods over the horizon is found to minimize the holding cost of finished product inventory of the customer orders completed before their due dates. Finally, the manufacturing and delivery schedules of the required parts are determined independently for each supplier to minimize the total cost of holding the inventory of parts, of start ups the production lines and of shipments the parts from the supplier to the producer.

\section{Conditions for feasibility of customer due dates}

In this section some necessary conditions are derived under which all customer due dates can be met.

Let $c_{g t}$ be the total processing time available in period $t$ on each machine in stage $g$ and $C_{g}(t, d)=m_{g} \sum_{\tau \in T: t \leq \tau \leq d} c_{g \tau}$ the total cumulative capacity available in stage $g$ in periods $t$ through $d$.

A necessary condition to have a feasible production schedule with all the customer orders completed by the producer during the planning horizon is that for each assembly stage $g \in G$ the total demand on capacity does not exceed total available capacity, i.e.

$$
\max _{g \in G}\left(\frac{\sum_{j \in J} o_{j} p_{g j}}{C_{g}(1, h)}\right) \leq 1
$$

Furthermore, all the customer orders can be completed by the producer on or before their due dates if the following necessary condition holds (Sawik 2006, 2007a)

$$
P C R(d)=\max _{g \in G}\left(P C R_{g}(d)\right) \leq 1 ; d \in T
$$

where $P C R_{g}(d)$ is the producer cumulative capacity ratio for due date $d$ with respect to processing stage $g$

$$
P C R_{g}(d)=\max _{t \in T: t \leq d}\left(\frac{\sum_{j \in J: t \leq a_{j} \leq d_{j} \leq d} o_{j} p_{g j}}{C_{g}(t, d)}\right) ; d \in T, g \in G
$$

Notice, that if $\operatorname{PCR}_{g}(d) \leq 1$, then for any period $t \leq d$, the cumulative demand on capacity in stage $g$ of all the orders with due dates not greater than $d$ and ready dates not less than $t$ (numerator in (3)) does not exceed the cumulative capacity available in this stage in periods $t$ through $d$ (denominator in (3)). 
The amount $c_{g t}$ of processing time available in period $t$ on each machine in stage $g$ must take into account the flowshop configuration of the production system and the transfer lot sizes to ensure that all products are completed in the same planning period at all upstream stages $1, \ldots, g-1$ and at all downstream stages $g+1, \ldots, f$ (see, Sawik 2006, 2007a). As a result the available capacity $c_{g t}$ is smaller than simply the available machine hours in period $t$.

Assuming that the producer capacity is time-invariant, that is, $c_{g t}=c_{g} \forall t \in T$, the cumulative capacity $C_{g}(t, d)$ in (3) can be calculated as below:

$$
C_{g}(t, d)=c_{g} m_{g}(d-t+1) ; g \in G, d, t \in T: t \leq d
$$

A similar feasibility condition can be derived for the suppliers under the worst case scenario, when each production line starts up in every period.

Let $c^{i}(t)$ be the manufacturing and delivery capacity of supplier $i$ in period $t$ and $C^{i}(d)=$ $\sum_{t \in T: t \leq d} c^{i}(t)$ the cumulative manufacturing and delivery capacity of supplier $i$ until period $d$. In addition denote by $J(i) \subset J$ the subset of customer orders such for which the required parts are provided by supplier $i$, where $\bigcup_{i \in I} J(i)=J$ and $\bigcap_{i \in I} J(i)=\emptyset$.

The required parts for all customer orders can be manufactured and delivered by their due dates if the following necessary condition holds

$$
S C R=\max _{i \in I} S C R(i) \leq 1
$$

where $S C R(i)$ is cumulative capacity ratio for supplier $i$

$$
S C R(i)=\max _{d \in T}\left(\frac{\sum_{k \in K} q_{i k} \sum_{l \in L} \sum_{j \in J_{l} \cap J(i): d_{j} \leq d} b_{k l} o_{j}}{C^{i}(d)}\right)
$$

If $S C R \leq 1$, then for all due dates $d$, the cumulative demand on capacity necessary to manufacture and deliver all parts required for the customer orders due not later than $d$ (numerator in $(6)$ ) does not exceed the suppliers cumulative capacity available by period $d$ (denominator in (6)).

For the worst case scenario, where each production line starts up in every period, $c^{i}(t)$ can be calculated as below

$$
c^{i}(t)=\left\{\begin{array}{cl}
0 & \text { if } t \leq-e_{i}+\theta_{i} \\
M_{i}\left(H-\sigma_{i}\right) & \text { if } t>-e_{i}+\theta_{i}
\end{array}\right.
$$

i.e., no parts from supplier $i$ can be delivered earlier than $\theta_{i}$ periods after the earliest period $-e_{i}$ of manufacturing. 
If the allocation of customer orders among the suppliers for parts provision is not known beforehand, an approximate cumulative capacity ratio can be defined as below.

$$
S \tilde{C} R=\max _{d \in T}\left(\frac{\sum_{k \in K} \tilde{q}_{k} \sum_{l \in L} \sum_{j \in J_{l}: d_{j} \leq d} b_{k l} o_{j}}{\sum_{i \in I} C^{i}(d)}\right)
$$

where $\tilde{q}_{k}$ is the average processing time required to manufacture one unit of part type $k$.

If all customer orders were continuously allocated among the consecutive time periods so that all periods could be filled exactly to their capacities, the necessary conditions (2) and (5) could become sufficient for all orders to be completed by their due dates. However, due to the discrete nature of indivisible, in particular, single-period customer orders that cannot be continuously allocated among the consecutive periods, it is possible that some planning periods will not be filled exactly to their capacities. As a result the necessary conditions (2) and (5) are not sufficient for all orders to be scheduled by their due dates.

The necessary conditions for feasibility of the customer requested due dates are checked at the top level of the proposed hierarchical approach (see, Section 5), where the primary objective is to maximize customer service level. If the feasibility conditions are satisfied for all requested due dates, then no tardy order occurs. Otherwise, to reach feasibility later due dates must be committed for some customer orders to minimize the number of tardy orders, i.e. the orders with committed due dates later than the requested due dates.

\section{Integrated supply chain scheduling: monolithic approach}

In this section a multi-objective mixed integer program INT is presented for the integrated scheduling of products assembly and parts manufacturing and supply in a customer driven supply chain.

\subsection{Decision variables}

Table 2. Notation: decision variables

Let $T^{(i)}$ be the enlarged, ordered set of planning periods with $e_{i}$ periods added before period $t=1$, that is

$$
T^{(i)}=\left\{-e_{i}, \ldots-1\right\} \bigcup T=\left\{-e_{i}, \ldots-1,1, \ldots h\right\} .
$$

The various decision variables (Table 2) used in model INT to coordinate different types of schedules in the supply chain are additionally explained below. 
- Manufacturing schedule for each supplier $i \in I$ :

- the set-up variable $r_{i k t}$ that describes a state of manufacturing system of each supplier in each planning period, i.e., the number of production lines of supplier $i$ set up to manufacture part type $k$ in period $t \in T^{(i)}$,

- the start-up variable $s_{i k t}$ that represents the number of production lines of supplier $i$ which are started up to manufacture part type $k$ in period $t \in T^{(i)}$, i.e., the number of lines of supplier $i$, set up in period $t \in T^{(i)}$ for part type $k$, which has not been set up for this part type in the previous period $\operatorname{prev}\left(t, T^{(i)}\right)$. The start-up variable can take a positive value only if the corresponding set-up variable has in period $t$ higher value than in period $\operatorname{prev}\left(t, T^{(i)}\right)$, i.e.

$$
s_{i k t}=\max \left\{0, r_{i k t}-r_{i k, p r e v\left(t, T^{(i)}\right)}\right\} .
$$

- the manufacturing lot variable $u_{i k t}$ that represents the lot size for of each part type manufactured by each supplier in each planning period, i.e.,the number of parts type $k$ manufactured in period $t \in T^{(i)}$ by supplier $i$.

- Delivery schedule for each supplier $i \in I$ :

- the delivery lot variable $v_{i k t}$ that represents the lot size of each part type delivered from each supplier to the producer in each planning period, i.e., the number of parts type $k$ delivered in period $t \in T^{(i)}$ from supplier $i$,

- the delivery timing variable $w_{i t}=1$, if delivery of parts from supplier $i$ is scheduled for period $t \in T^{(i)}$, otherwise $w_{i t}=0$.

- Assembly schedule for customer orders:

- the order assignment and supplier selection variable $\zeta_{i j t}=1$, if customer order $j$ is supplied with parts by supplier $i$ and assigned for processing to planning period $t \in T$; otherwise $\zeta_{i j t}=0$.

\subsection{Multi-objective mixed integer program}

The objective of the integrated scheduling is to allocate customer orders among the suppliers of parts, to determine for each supplier a schedule of manufacturing parts and a schedule of supply the parts to the producer, and to find for the producer a schedule of assembly the ordered products, so as to maximize customer service level or equivalently to minimize the number of tardy orders, as a primary optimality criterion. Simultaneously, to achieve a 
low unit cost, total supply chain inventory holding cost and cost of production line start-ups and part shipments are minimized. Thus, the secondary objective functions are minimization of the total inventory holding cost and minimization of production line startups and part shipment costs. The three objective functions, numbered according to their nonincreasing importance are defined below.

Number of tardy orders

$$
f_{1}=\sum_{i \in I} \sum_{j \in J} \sum_{t \in T: t>d_{j}} \zeta_{i j t}
$$

The cost of inventory holding

$$
\begin{array}{r}
f_{2}=\sum_{k \in K} \sum_{i \in I_{k}} \sum_{t \in T} \sum_{\tau \in T^{(i)}: \tau \leq t} \varphi_{1 i k}\left(u_{i k \tau}-v_{i k, n e x t}\left(\tau, T^{(i)}, \theta_{i}\right)\right. \\
+\sum_{k \in K} \sum_{i \in I_{k}} \sum_{t \in T: t \geq n e x t\left(-e_{i}, T^{(i)}, \theta_{i}\right)} \varphi_{2 i k} \theta_{i} v_{i k t} \\
+\sum_{k \in K} \sum_{i \in I_{k}} \sum_{t \in T} \varphi_{3 k}\left(\sum_{\tau \in T^{(i)}: \tau \leq t} v_{i k \tau}-\sum_{l \in L} \sum_{j \in J_{l}} \sum_{\tau=1}^{t} b_{k l} o_{j} \zeta_{i j \tau}\right) \\
+\sum_{i \in I} \sum_{t \in T} \sum_{\tau=1}^{t} \sum_{j \in J: d_{j}>t} \varphi_{4 j} o_{j} \zeta_{i j \tau}
\end{array}
$$

where $\varphi_{1 i k}, \varphi_{2 i k}, \varphi_{3 k}$, and $\varphi_{4 j}$ are the unit holding costs of parts stored at supplier $i$, of parts being intransit from supplier $i$ to producer, of parts stored at producer, and of finished products stored at producer, respectively.

The cost of production line start-ups and part shipments

$$
f_{3}=\sum_{i \in I} \sum_{k \in K} \sum_{t \in T^{(i)}} \psi_{1 i k}\left(\sigma_{i} / q_{i k}\right) s_{i k t}+\sum_{i \in I} \sum_{t \in T^{(i)}} \psi_{2 i} \theta_{i} w_{i t}
$$

where $\psi_{1 i k}, \psi_{2 i}$ are the unit start-up, shipment costs, respectively.

For each supplier $i$ the start-up cost is measured by the total production of parts lost due to line start-ups, whereas the fixed shipment cost is proportional to the total transportation time.

Notice that total cost of transportation parts from suppliers to producer consists of variable intransit holding cost and fixed shipment cost.

Model INT: Multi-objective integrated scheduling of manufacturing, supply and assembly

$$
\min f_{1}, f_{2}, f_{3}
$$

subject to 


\section{Customer order assignment constraints}

- each customer order is assigned to exactly one supplier and to exactly one planning period,

$$
\sum_{i \in I} \sum_{t \in T: a_{j} \leq t} \zeta_{i j t}=1 ; j \in J
$$

\section{Producer capacity constraints}

- in every period the demand on capacity at each assembly stage cannot be greater than the maximum available capacity in this period,

$$
\sum_{i \in I} \sum_{j \in J} o_{j} p_{g j} \zeta_{i j t} \leq m_{g} c_{g t} ; g \in G, t \in T
$$

\section{Manufacturing line set-up and start-up constraints for each supplier}

- in every period total number of production lines set up for manufacturing different part types is not greater than total number $M_{i}$ of available lines,

- all production lines set up for part type $k$ in the beginning period should be started up to manufacture this part type,

- in every period $t$, the number of production lines started up for part type $k$ cannot be less than the difference between the number of lines set up for this part type in period $t$ and in the previous period $\operatorname{prev}\left(t, T^{(i)}\right)$,

- in every period $t$, the number of production lines started up for part type $k$ cannot be greater than the number of lines set up for part type $k$ in this period and cannot be greater than the number of lines set up for the other part types or idle in the previous period $\operatorname{prev}\left(t, T^{(i)}\right)$,

$$
\begin{array}{r}
\sum_{k \in K} r_{i k t} \leq M_{i} ; i \in I, t \in T^{(i)} \\
s_{i, k,-e_{i}}=r_{i, k,-e_{i}} ; i \in I, k \in K \\
s_{i k t} \geq r_{i k t}-r_{i k, p r e v\left(t, T^{(i)}\right)} ; i \in I, k \in K, t \in T^{(i)}: t>-e_{i} \\
s_{i k t} \leq r_{i k t} ; i \in I, k \in K, t \in T^{(i)} \\
s_{i k t} \leq M_{i}-r_{i k, p r e v\left(t, T^{(i)}\right)} ; i \in I, k \in K, t \in T^{(i)}: t>-e_{i}
\end{array}
$$

\section{Manufacturing capacity constraints for each supplier}

- in every period $t$ the production volume of part type $k$ cannot be greater than the maximum volume corresponding to the capacity assigned to part type $k$ in this period,

$$
u_{i k t} \leq\left\lfloor\left(H-\sigma_{i}\right) / q_{i k}\right\rfloor s_{i k t}+\left\lfloor H / q_{i k}\right\rfloor\left(r_{i k t}-s_{i k t}\right) ; i \in I, k \in K, t \in T^{(i)}
$$


where $\lfloor\cdot\rfloor$ is the greatest integer not greater than $\cdot$

5. Part manufacturing and delivery constraints for each supplier

- for each part type the cumulative delivery by period $t$ cannot be greater than the cumulative manufacturing of this part type by period $\operatorname{prev}\left(t, T^{(i)}, \theta_{i}\right)$, i.e., manufactured not later than $\theta_{i}$ periods before period $t$,

- parts can be delivered only in periods scheduled for delivery and each shipment is limited by its minimum and maximum capacity, respectively $\underline{V}$ and $\bar{V}$,

- no delivery from supplier $i$ can be scheduled before period next $\left(-e_{i}, T^{(i)}, \theta_{i}\right)$, i.e., no delivery can be scheduled earlier than $\theta_{i}$ periods after the earliest period $-e_{i}$ of manufacturing,

$$
\begin{array}{r}
\sum_{\tau \in T^{(i)}: \tau \leq t} v_{i k \tau} \leq \sum_{\tau \in T^{(i)}: \tau \leq \operatorname{prev}\left(t, T^{(i)}, \theta_{i}\right)} u_{i k \tau} ; i \in I, k \in K, t \in T^{(i)}: \\
\sum_{t \in T^{(i)}} v_{i k t}=\sum_{\begin{array}{r}
t \in T^{(i)}: t \leq p r e v\left(h, T^{(i)}, \theta_{i}\right) \\
v_{i k t} \leq \bar{V} w_{i t} ; i \in I, k \in K, t \in T^{(i)}
\end{array}} u_{i k t} ; i \in I, k \in K \\
\sum_{k \in K} v_{i k t} \leq \bar{V} ; i \in I, t \in T^{(i)} \\
\sum_{k \in K} v_{i k t} \geq \underline{V} w_{i t} ; i \in I, t \in T^{(i)} \\
v_{i k t}=0 ; i \in I, k \in K, t \in T^{(i)}: t<\operatorname{next}\left(-e_{i}, T^{(i)}, \theta_{i}\right) \\
w_{i t}=0 ; i \in I, t \in T^{(i)}: t<\operatorname{next}\left(-e_{i}, T^{(i)}, \theta_{i}\right)
\end{array}
$$

\section{Part demand satisfaction constraints}

- for each part type $k$ the cumulative deliveries from supplier $i$ by period $t$ cannot be less than the cumulative demand for this part type by this period,

-total delivery of each part type $k$ from all suppliers is equal to the total demand for this part type,

$$
\begin{array}{r}
\sum_{\tau \in T^{(i)}: \tau \leq t} v_{i k \tau} \geq \sum_{l \in L} \sum_{j \in J_{l}} \sum_{\tau=1}^{t} b_{k l} o_{j} \zeta_{i j \tau} ; i \in I, k \in K, t \in T^{(i)}: t<h \\
\sum_{i \in I} \sum_{t \in T^{(i)}} v_{i k t}=\sum_{l \in L} \sum_{j \in J_{l}} b_{k l} o_{j} ; k \in K
\end{array}
$$

\section{Coordinating constraints}

- the cumulative requirement for each part type $k$ from each supplier $i$ of the orders assigned to periods 1 through $t$ and to supplier $i$ (right hand side of (30)) cannot be greater than the total production at supplier $i$ of this part type by period $\operatorname{prev}\left(t, T^{(i)}, \theta_{i}\right)$, i.e., manufactured 
at $i$ not later than $\theta_{i}$ periods before period $t$ (left hand side of (30))

$$
\begin{array}{r}
\left\lfloor H / q_{i k}\right\rfloor \sum_{\tau \in T^{(i)}:} \sum_{\tau \leq \operatorname{prev}\left(t, T^{(i)}, \theta_{i}\right)}\left(r_{i k \tau}-s_{i k \tau}\right)+\left\lfloor\left(H-\sigma_{i}\right) / q_{i k}\right\rfloor \sum_{\tau \in T^{(i)}: \tau \leq \operatorname{prev}\left(t, T^{(i)}, \theta_{i}\right)} s_{i k \tau} \\
\geq \sum_{l \in L} \sum_{j \in J_{l}} \sum_{\tau=1}^{t} b_{k l} o_{j} \zeta_{i j \tau} ; i \in I, k \in K, t \in T^{(i)}: t \geq \operatorname{next}\left(-e_{i}, T^{(i)}, \theta_{i}\right)
\end{array}
$$

8. Nonnegativity and integrality conditions

$$
\begin{array}{r}
r_{i k t} \geq 0, \text { integer; } i \in I, k \in K, t \in T^{(i)} \\
s_{i k t} \geq 0, \text { integer; } i \in I, k \in K, t \in T^{(i)} \\
u_{i k t} \geq 0 ; i \in I, k \in K, t \in T^{(i)} \\
v_{i k t} \geq 0 ; i \in I, k \in K, t \in T^{(i)} \\
w_{i t} \in\{0,1\} ; i \in I, t \in T^{(i)} \\
\zeta_{i j t} \in\{0,1\} ; i \in I, j \in J, t \in T: a_{j} \leq t
\end{array}
$$

The coordinating constraint (30) has been introduced to strengthen the mixed integer program INT as it directly links the assignment of production lines to parts types over the planning horizon (variables $r_{i k t}$ and $s_{i k t}$ ) and the assignment of customer orders to planning periods and to suppliers (variable $\zeta_{i j t}$ ). Thus, (30) directly coordinates the suppliers schedules and the producer schedule. (30) is implied by constraints (20), (21) and (28), and any feasible solution that satisfies (30) satisfies also (20), (21) and (28).

\subsection{Selected solution approaches}

This subsection provides a brief description of selected approaches that can be used to determine the non-dominated solution set of the multi-objective mixed integer program INT.

\section{Weighted-sum program}

The non-dominated solution set of the multi-objective program INT can be partially determined by the parameterization on $\lambda$ the following weighted-sum program.

Model $\mathrm{INT}_{\lambda}$

$$
\min \sum_{\iota=1}^{3} \lambda_{\iota} f_{\iota}
$$

subject to (13) - (36),

where $\lambda_{1}>\lambda_{2}>\lambda_{3}>0, \lambda_{1}+\lambda_{2}+\lambda_{3}=1$. 
It is well known, however, that the non-dominated solution set of a multi-objective integer program such as $\mathbf{I N} \mathbf{T}_{\lambda}$ cannot be fully determined even if the complete parameterization on $\lambda$ is attempted, e.g. Steuer (1986). To compute unsupported non-dominated solutions, some upper bounds on the objective functions should be added to $\mathbf{I N T}_{\lambda}$, e.g. Alves and Climaco (2007).

\section{Reference point based scalarizing program}

Let $\bar{f}=\left(\bar{f}_{1}, \bar{f}_{2}, \bar{f}_{3}\right)$ be a reference point in the criteria space such that $\bar{f}_{\iota}<f_{\iota}, \forall \iota$ for all feasible solutions satisfying (13)-(36), and denote by $\rho$ a small positive value. The non-dominated solution set of the multi-objective program INT can be found by the parameterization on $\omega$ the following mixed integer program $\mathbf{I N T}^{\omega}$.

\section{Model INT ${ }^{\omega}$}

$$
\min \left\{\delta-\rho \sum_{\iota=1}^{3} f_{\iota}\right\}
$$

subject to $(13)-(36)$ and

$$
\begin{array}{r}
\omega_{\iota}\left(f_{\iota}-\bar{f}_{\iota}\right) \leq \delta ; \iota=1,2,3 \\
\delta \geq 0
\end{array}
$$

Program INT ${ }^{\omega}$ is based on the augmented $\omega$-weighted Tchebysheff metric $\max _{\iota=1,2,3}\left\{\omega_{\iota} \mid f_{\iota}-\right.$ $\left.\bar{f}_{\iota} \mid\right\}$, where $\omega_{\iota} \geq 0, \forall \iota$ and $\sum_{\iota=1}^{3} \omega_{\iota}=1$.

\section{Lexicographic approach}

Considering the relative importance of the three objective functions (9)-(11), the multiobjective program INT can replaced with a sequence INT(1), INT(2), INT(3) of the following three single objective mixed integer programs to be solved subsequently.

Model $\operatorname{INT}(\iota), \iota=1,2,3$

$$
\min f_{\iota}
$$

subject to (13) - (36) and

$$
f_{l}=f_{l}^{*} ; l<\iota: \iota>1
$$


where $f_{\iota}^{*}$ is the optimal solution value to the mixed integer program $\operatorname{INT}(\iota), \iota=1,2$.

The hierarchical decomposition scheme for the multi-objective integrated scheduling proposed in the next section is based on the lexicographic approach.

\subsection{Multi-period orders}

Model INT is capable of scheduling single-period orders only, where each order can be fully processed in a single time period. In some cases, in addition to single-period orders, also large-size, divisible orders should be considered, where each order cannot be completed in one period and must be split into single-period portions to be processed in a subset of consecutive time periods. The large size orders are referred to as multi-period orders.

In some practical cases, the two types of customer orders must be scheduled simultaneously. Denote by $J 1 \subseteq J$, and $J 2 \subseteq J$, respectively the subset of indivisible and divisible orders, respectively, where $J 1 \cup J 2=J$, and $J 1 \cap J 2=\emptyset$.

The mixed integer program INT can be enhanced to simultaneously schedule both the single- and the multi-period orders. In addition to order assignment and supplier selection binary variable $\zeta_{i j t}$, a new order allocation continuous variable $\xi_{i j t}$ must be introduced, where $\xi_{i j t} \in[0,1]$ denotes a fraction of a multi-period order $j$ assigned to period $t$ and provided with parts by supplier $i$.

Model INT can be enhanced as follows. In definition (10) of $f_{2}$ and in constraints (13), (14), (28) and (30), the binary assignment variable $\zeta_{i j t}$ should be replaced with continuous allocation variable $\xi_{i j t}$. Then, the modified (13) will ensure that each order is assigned to exactly one supplier and is completed during the planning horizon. In addition, the following new constraints should be added to INT:

Order assignment constraints

- each single-period order is assigned to exactly one planning period and to exactly one supplier,

$$
\sum_{i \in I} \sum_{t \in T: a_{j} \leq t} \zeta_{i j t}=1 ; j \in J 1
$$

- each multi-period order is assigned to a subset of consecutive planning periods and a single supplier,

$$
\zeta_{i j\left\lfloor\left(\tau_{1}+\tau_{2}\right) / 2\right\rfloor} \geq \zeta_{i j \tau_{1}}+\zeta_{i j \tau_{2}}-1 ; i \in I, j \in J 2, \tau_{1}, \tau_{2} \in T: a_{j} \leq \tau_{1}<\tau_{2}
$$

Order allocation constraints

- each single-period order must be completed in a single period,

$$
\zeta_{i j t}=\xi_{i j t} ; i \in I, j \in J 1, t \in T: a_{j} \leq t
$$


- each multi-period order is allocated among all the periods that are selected for its assignment,

$$
\xi_{i j t} \leq \zeta_{i j t} ; i \in I, j \in J 2, t \in T: a_{j} \leq t .
$$

Nonnegativity conditions

$$
\xi_{i j t} \in[0,1] ; i \in I, j \in J, t \in T: a_{j} \leq t
$$

While the focus in this paper is on single-period customer orders, the ideas presented in the sequel may as well be applied for scheduling the multi-period orders.

\section{Integrated supply chain scheduling: hierarchical approach}

Figure 2. Hierarchical scheduling of customer orders and manufacturing and delivery of parts.

In this section the integer programming formulations are presented for a hierarchical scheduling of customer orders and manufacturing and supplies of parts. The proposed hierarchical approach can be applied within a pull planning framework in customer driven supply chains. The hierarchical decomposition scheme is based on the lexicographic approach (see, Section 4.3). However, in addition to the vertical decomposition driven by relative importance of the objective functions, it also utilizes the horizontal decomposition enabled by the allocation of customer orders among the suppliers. The hierarchical framework consists of the following three decision making problems to be solved sequentially (Fig 2):

1. Rough-cut capacity allocation - RCA,

2. Non-delayed scheduling of customer orders - NDS,

3. Scheduling manufacturing and delivery of parts from each supplier - $\mathbf{S M D}(i)$.

Unlike the detailed formulations INT(1) and INT(2) of the lexicographic approach, the top level problem RCA accounts for the cumulative capacity constraints of the producer, and both the top and the middle level problems RCA and NDS contain the worst case capacity constraints of the suppliers, where all production lines are assumed to be started up in each planning period. However, a feasible solution to RCA that satisfies the cumulative capacity constraints of the producer would not necessary lead to a feasible, non-delayed schedule of customer orders at the middle level NDS, if greater capacity of the suppliers were allowed at the top level. This is due to the fact that some periods may not be filled exactly to their 
capacities since the discrete and, in particular, single-period orders cannot be continuously allocated among the consecutive periods.

Furthermore, to decrease the computational effort required for scheduling customer orders for the producer, the top level problem RCA sets delayed due dates for some orders to meet conditions (2) and (5), and by this the middle level problem is reduced to a nondelayed scheduling problem. This coincides with a typical industrial practice, where the order acceptance and due date setting decisions made by the sales departments precede any scheduling decisions. However, in contrast to the common practice, where the sales and the production departments often work independently, the committed due dates determined at the top level must satisfy the available capacity of both the suppliers and the producer.

The objective of the top level problem RCA is to select a supplier of parts for each customer order, to determine the maximal subset of orders that can be completed by the customer requested due dates and to update (delay) due dates for the remaining orders to meet the capacity constraints.

Given the supplier of parts and the due date for each customer order, the objective of the middle level problem NDS is to determine a feasible, non-delayed assignment of orders to planning periods over the planning horizon to minimize the finished product inventory holding cost of customer orders completed before their due dates.

Finally, given the cumulative requirements for all part types from each supplier, the objective of the base level problem $\operatorname{SMD}(i)$ is to determine the integrated manufacturing and delivery schedule of parts independently for each supplier such that the weighted cost of manufacturing and supplies of parts and holding the inventory of parts in the supply chain is minimized.

The integer programs RCA, NDS and $\mathbf{S M D}(i)$ are presented below (for notation used and definitions of the decision variables, see Table 1 and Table 2).

The integer program RCA contains the following two decision variables.

- Order acceptance and supplier selection variable: $x_{i j}=1$, if order $j$ is accepted with its customer requested due date and assigned to supplier $i ; x_{i j}=0$ if order $j$ needs delaying to be accepted,

- Due date setting and supplier selection variable: $y_{i j t}=1$, if order $j$ unacceptable with requested due date (with $\sum_{i \in I} x_{i j}=0$ ) is assigned a later due date $t,\left(t>d_{j}\right)$ and is selected for supplier $i$; otherwise $y_{i j t}=0$. 


\subsection{Rough-cut capacity allocation}

Model RCA: Rough-cut capacity allocation

Minimize the number of tardy orders

$$
f_{1}=\sum_{j \in J}\left(1-\sum_{i \in I} x_{i j}\right)
$$

subject to

1. Supplier selection, order acceptance or due date setting constraints:

- each customer order is assigned to exactly one supplier and is either accepted with its requested due date or is assigned a later due date to reach production and delivery schedule feasibility,

- no customer order with a due date earlier than the first delivery of parts from a supplier can be assigned to that supplier,

$$
\begin{array}{r}
\sum_{i \in I} x_{i j}+\sum_{i \in I} \sum_{t \in T: t>d_{j}} y_{i j t}=1 ; j \in J \\
x_{i j}=0 ; i \in I, j \in J: d_{j}<\operatorname{next}\left(-e_{i}, T^{(i)}, \theta_{i}\right) \\
y_{i j t}=0 ; i \in I, j \in J, t \in T: d_{j}<t<\operatorname{next}\left(-e_{i}, T^{(i)}, \theta_{i}\right)
\end{array}
$$

\section{Producer cumulative capacity constraints:}

- for any period $t \leq d$, the cumulative demand on capacity in stage $g$ of all the customer orders accepted with requested (or adjusted) due dates not greater than $d$ and ready dates (or requested due dates, respectively) not less than $t$ must not exceed the cumulative capacity available in this stage in periods $t$ through $d$

$$
\begin{array}{r}
\sum_{i \in I} \sum_{j \in J: t \leq a_{j} \leq d_{j} \leq d} o_{j} p_{g j} x_{i j}+\sum_{i \in I} \sum_{j \in J} \sum_{\tau \in T: t \leq d_{j}<\tau \leq d} o_{j} p_{g j} y_{i j \tau} \leq C_{g}(t, d) \\
d, t \in T, g \in G: t \leq d
\end{array}
$$

\section{Supplier cumulative capacity constraints}

- the cumulative demand on manufacturing capacity for parts required in periods 1 through $t$ for the customer orders assigned to supplier $i$ cannot be greater than the available cumulative capacity of this supplier by period $t$,

$$
\sum_{k \in K} \sum_{l \in L} b_{k l} q_{i k}\left(\sum_{j \in J_{l}: d_{j} \leq t} o_{j} x_{i j}+\sum_{j \in J_{l}} \sum_{\tau \in T: d_{j}<\tau \leq t} o_{j} y_{i j \tau}\right) \leq C^{i}(t) ; i \in I, t \in T
$$




\section{Integrality conditions}

$$
\begin{array}{r}
x_{i j} \in\{0,1\} ; i \in I, j \in J \\
y_{i j t} \in\{0,1\} ; i \in I, j \in J, t \in T: t>d_{j}
\end{array}
$$

The assumption of the time-invariant capacity of the producer (4) and the worst case capacity of the suppliers (7) allows the producer cumulative capacity constraints (47) and the supplier cumulative capacity constraints (47) to be replaced with the following constraints (51) and (52), (53), (54), respectively

$$
\begin{array}{r}
\sum_{i \in I}\left(\sum_{j \in J: t \leq a_{j} \leq d_{j} \leq d} o_{j} x_{i j} / \pi_{g j}+\sum_{j \in J} \sum_{\tau \in T: t \leq d_{j}<\tau \leq d} o_{j} y_{i j \tau} / \pi_{g j}\right) \leq m_{g}(d-t+1) \\
d, t \in T, g \in G: t \leq d \\
\sum_{l \in L} \sum_{j \in J_{l}: d_{j} \leq t} b_{k l} o_{j} x_{i j} / \rho_{i k}+\sum_{l \in L} \sum_{j \in J_{l}} \sum_{\tau \in T: d_{j}<\tau \leq t} b_{k l} o_{j} y_{i j \tau} / \rho_{i k} \leq \sum_{\tau=-e_{i}}^{p r e v\left(t, T^{(i)}, \theta_{i}\right)} r_{i k \tau} ; \\
i \in I, k \in K, t \in T^{(i)}: t \geq n e x t\left(-e_{i}, T^{(i)}, \theta_{i}\right) \\
\sum_{k \in K} r_{i k t} \leq M_{i} ; i \in I, t \in T^{(i)} \\
r_{i k t} \geq 0, \text { integer } ; i \in I, k \in K, t \in T^{(i)}
\end{array}
$$

where

$\pi_{g j}=\left\lfloor c_{g} / p_{g j}\right\rfloor$ is the one machine-period production rate for product type $l$ (such that $\left.j \in J_{l}\right)$ at assembly stage $g$, and

$\rho_{i k}=\left\lfloor\left(H-\sigma_{i}\right) / q_{i k}\right\rfloor$ is the one machine-period worst case manufacturing rate for part type $k$ at supplier $i$.

The capacity constraints (47), (48) ensure that each order $j \in J$ can be completed on or before its requested due date $d_{j}$ (if $\sum_{i \in I} x_{i j}=1$ ) or on its delayed due date $t>d_{j}$ (if $\sum_{i \in I} x_{i j}=0$ and $\sum_{i \in I} y_{i j t}=1$ ), see (2), (3) and (5), (6) in Section 3. If conditions (2) and (5) hold for all customer requested due dates, then problem RCA reduces to supplier selection for each order and the objective function $f_{1}$ (43) takes on zero value, since $\sum_{i \in I} x_{i j}=1 \forall j \in J$ and $\sum_{i \in I} y_{i j t}=0 \forall j \in J, t \in T: t>d_{j}$.

The solution to the integer program RCA determines the maximal subset $\{j \in J$ : $\left.\sum_{i \in I} x_{i j}=1\right\}$ of customer orders accepted with the customer requested due dates $d_{j}$ and the subset of the remaining orders $\left\{j \in J: \sum_{i \in I} x_{i j}=0\right\}$ with the updated (delayed) due 
dates. Denote by $D_{j}$, the requested or updated due date for each order $j \in J$, i.e.,

$$
D_{j}=\left\{\begin{array}{cl}
d_{j} & \text { if } j \in\left\{j \in J: \sum_{i \in I} x_{i j}=1\right\} \\
\sum_{i \in I} \sum_{t \in T: t>d_{j}} t y_{i j t} & \text { if } j \in\left\{j \in J: \sum_{i \in I} x_{i j}=0\right\}
\end{array}\right.
$$

Furthermore, a supplier has been selected for each order to provide the required parts and let $J(i)=\left\{j \in J: x_{i j}=1\right.$ or $\left.\sum_{t \in T: t>d_{j}} y_{i j t}=1\right\} \subset J$ be the subset of orders assigned to supplier $i \in I$.

\subsection{Non-delayed scheduling of customer orders}

Given the updated due dates $D_{j}, j \in J$ and the allocation $J(i), i \in I$ of the customer orders among the suppliers, the next decision step is to determine a non-delayed assembly schedule for the producer, that is, the assignment of customer orders to planning periods by their due dates over the horizon to minimize the finished products inventory holding cost.

The basic order assignment and supplier selection variable $\zeta_{i j t}$ used in the monolithic model INT, below is replaced by the order assignment variable $z_{j t}=1$, if customer order $j$ is assigned to planning period $t$; otherwise $z_{j t}=0$.

Model NDS: Non-delayed scheduling of customer orders

Minimize the holding cost of finished product inventory

$$
f_{20}=\sum_{t \in T} \sum_{\tau=1}^{t} \sum_{j \in J: d_{j}>t} \varphi_{4 j} o_{j} z_{j \tau}
$$

subject to

1. Customer order non-delayed assignment constraints

- each customer order is assigned to exactly one planning period not later than its due date,

$$
\sum_{t \in T: a_{j} \leq t \leq D_{j}} z_{j t}=1 ; j \in J
$$

\section{Producer capacity constraints}

- in every period the demand on capacity at each assembly stage cannot be greater than the maximum available capacity in this period,

$$
\sum_{j \in J} o_{j} z_{j t} / \pi_{g j} \leq m_{g} ; g \in G, t \in T
$$

3. Supplier cumulative capacity constraints 
- the cumulative demand on manufacturing capacity for parts required in periods 1 through $t$ for the customer orders assigned to supplier $i$ cannot be greater than the available cumulative capacity of this supplier by period $t$,

$$
\begin{array}{r}
\sum_{l \in L} \sum_{j \in J_{l} \cap J(i)} \sum_{\tau \in T:} b_{a_{j} \leq \tau \leq D_{j}, \tau \leq t} b_{k l} o_{j} z_{j \tau} / \rho_{i k} \leq \sum_{\tau=-e_{i}}^{\operatorname{prev}\left(t, T^{(i)}, \theta_{i}\right)} r_{i k \tau} \\
i \in I, k \in K, t \in T: t \geq \operatorname{next}\left(-e_{i}, T^{(i)}, \theta_{i}\right) \\
\sum_{k \in K} r_{i k t} \leq M_{i} ; i \in I, t \in T^{(i)}
\end{array}
$$

4. Integrality conditions

$$
\begin{gathered}
r_{i k t} \geq 0, \text { integer } ; i \in I, k \in K, t \in T^{(i)} \\
z_{j t} \in\{0,1\} ; j \in J, t \in T: a_{j} \leq t \leq D_{j}
\end{gathered}
$$

In order to better utilize the manufacturing capacity of suppliers, the worst case manufacturing rates $\rho_{i k}$ can be replaced with the average manufacturing rates $\bar{\rho}_{i k}$, where $\bar{\rho}_{i k}=\left\lfloor\left(H-\sigma_{i} \gamma_{i} / h\right) / q_{i k}\right\rfloor$ is the one machine-period average manufacturing rate for part type $k$ at supplier $i$, and $\gamma_{i} \leq h$ is the average number of production line start-ups at supplier $i$ over the planning horizon.

\subsection{Scheduling manufacturing and delivery of parts}

The solution to NDS determines the optimal assignment of customer orders to planning periods $\left\{z_{j t}, j \in J, t \in T\right\}$ and thereby the optimal assembly schedule for the finished products. Denote by $O_{i k t}$ the optimal cumulative usage in periods 1 through $t$ of part type $k$ delivered by supplier $i$, i.e., the optimal cumulative requirement for part type $k$ provided by supplier $i$

$$
O_{i k t}=\sum_{l \in L} \sum_{j \in J_{l} \bigcap J(i)} \sum_{\tau=1}^{t} b_{k l} o_{j} z_{j \tau} ; i \in I, k \in K, t \in T
$$

Now, the base level problem can be formulated. Given the cumulative requirements $O_{i k t}, t \in T$ for all part types $k \in K$ from each supplier $i \in I$ by each period $t$, determine the manufacturing and the delivery schedule of parts, independently for each supplier. In the integer program $\mathbf{S M D}(i)$ presented below, the supplier subscript $i$ is a fixed parameter that could be suppressed.

Model SMD $(i)$ : Scheduling manufacturing and delivery of parts for supplier $i$

Minimize the weighted cost of parts manufacturing, supplies and inventory holding

$$
\alpha f_{2 i}+(1-\alpha) f_{3 i}=
$$




$$
\begin{array}{r}
\alpha\left(\sum_{k \in K} \sum_{t \in T} \sum_{\tau \in T^{(i)}: \tau \leq t} \varphi_{1 i k}\left(u_{i k \tau}-v_{i k, n \operatorname{ext}\left(\tau, T^{(i)}, \theta_{i}\right)}\right)\right. \\
+\sum_{k \in K} \sum_{t \in T: t \geq \operatorname{next}\left(-e_{i}, T^{(i)}, \theta_{i}\right)} \varphi_{2 i k} \theta_{i} v_{i k t} \\
\left.+\sum_{k \in K} \sum_{t \in T} \varphi_{3 k}\left(\sum_{\tau \in T^{(i)}: \tau \leq t} v_{i k \tau}-O_{i k t}\right)\right) \\
+(1-\alpha) \sum_{t \in T^{(i)}}\left(\sum_{k \in K} \psi_{1 i k}\left(\sigma_{i} / q_{i k}\right) s_{i k t}+\psi_{2 i} \theta_{i} w_{i t}\right)
\end{array}
$$

where $0<\alpha<1$

1. Manufacturing line set-up and start-up constraints: (15) - (19) for supplier $i$

2. Manufacturing capacity constraints: (20) for supplier $i$

3. Part manufacturing and delivery constraints: (21) - (27) for supplier $i$

\section{Part demand satisfaction constraints}

- for each part type $k$ the cumulative deliveries from supplier $i$ by period $t$ cannot be less than the cumulative demand for this part type by this period,

-total delivery of each part type $k$ from supplier $i$ is equal to the total demand of this part type from this supplier,

$$
\begin{array}{r}
\sum_{\tau \in T^{(i)}: \tau \leq t} v_{i k \tau} \geq O_{i k t} ; k \in K, t \in T: t<h \\
\sum_{t \in T^{(i)}} v_{i k t}=O_{i k h} ; k \in K
\end{array}
$$

\section{Coordinating constraints}

- the total production of each part type at supplier $i$ by period $\operatorname{prev}\left(t, T^{(i)}, \theta_{i}\right)$, i.e., manufactured at $i$ not later than $\theta_{i}$ periods before period $t$ must not be less than the cumulative requirement for this part type by period $t$ of the orders assigned to supplier $i$

$$
\begin{array}{r}
\left\lfloor H / q_{i k}\right\rfloor \sum_{\tau \in T^{(i)}: \tau \leq \operatorname{prev}\left(t, T^{(i)}, \theta_{i}\right)}\left(r_{i k \tau}-s_{i k \tau}\right)+\left\lfloor\left(H-\sigma_{i}\right) / q_{i k}\right\rfloor \sum_{\tau \in T^{(i)}: \tau \leq \operatorname{prev}\left(t, T^{(i)}, \theta_{i}\right)} s_{i k \tau} \\
\geq O_{i k t} ; k \in K, t \in T^{(i)}: t \geq \operatorname{next}\left(-e_{i}, T^{(i)}, \theta_{i}\right)
\end{array}
$$

6. Nonnegativity and integrality conditions: (31) - (35) for supplier $i$.

The coordinating constraint (66) is implied by (20), (21) and (64), and it directly links the assignment of production lines of supplier $i$ to parts types over the planning horizon with the cumulative requirement for the part types from supplier $i$, (cf. (30)).

In the objective function (63), $f_{2 i}$ and $f_{3 i}$ are the inventory holding cost of parts manufactured by supplier $i$ and stored by the supplier and by the producer and the cost of supplier $i$ of production line start-ups and part shipments, respectively. 
Recall that in the hierarchical approach the total supply chain inventory holding cost is split among two decision levels. Thus, the final values of the objective functions $f_{2}(10)$ and $f_{3}$ (11) can be calculated as the sums of their partial solution values, determined for the middle level problem NDS and the base level problems $\mathbf{S M D}(i), i \in I$

$$
\begin{array}{r}
f_{2}=f_{20}+\sum_{i \in I} f_{2 i} \\
f_{3}=\sum_{i \in I} f_{3 i} .
\end{array}
$$

\section{Computational examples}

In this section some computational examples are presented to compare the monolithic and the hierarchical approach and to illustrate possible applications of the proposed mixed integer programming models. The examples are modeled after a real world customer driven supply chain for high-tech products.

A brief description of planning horizon, manufacturers/suppliers, producer, part types, product types and customer orders is given below.

1. Planning horizon: $h=14$ periods (days), each of length $H=2 \times 9$ hours.

2. Manufacturers/Suppliers

- $m=3$ suppliers:

supplier 1 with delivery time $\theta_{1}=1$ period, $M_{1}=12$ production lines and identical start-up time $\sigma_{1}=10000$ seconds for each line,

supplier 2 with delivery time $\theta_{2}=2$ periods, $M_{2}=11$ production lines and identical start-up time $\sigma_{2}=8000$ seconds for each line,

supplier 3 with delivery time $\theta_{3}=3$ periods, $M_{3}=10$ production lines and identical start-up time $\sigma_{3}=9000$ seconds for each line.

- the earliness of the manufacturing start in advance of the assembly start is $e_{i}=2$ days for each supplier $i=1,2,3$.

- the minimum and the maximum allowed shipment from each supplier: $\underline{V}=5000$, and $\bar{V}=50000$ parts,

- Parts

- 10 product-specific part types

- manufacturing times (in seconds) for part types: 


$\begin{array}{rrrr}\text { part type/supplier } & 1 & 2 & 3 \\ 1 & 65 & 60 & 70 \\ 2 & 70 & 75 & 65 \\ 3 & 80 & 75 & 85 \\ 4 & 85 & 80 & 90 \\ 5 & 90 & 95 & 85 \\ 6 & 95 & 90 & 100 \\ 7 & 65 & 60 & 70 \\ 8 & 75 & 70 & 65 \\ 9 & 90 & 80 & 100 \\ 10 & 85 & 80 & 90\end{array}$

- the unit inventory holding costs are $\varphi_{1 i k}=0.001, \varphi_{2 i k}=0.0015, \varphi_{3 k}=0.002, \varphi_{4 j}=$ $0.004 \forall i, k, j$, and the units start-up and shipment costs are $\psi_{1 i k}=0.004, \psi_{2 i}=$ $1 \forall i, k$.

3. Producer

- $f=6$ assembly stages in series with parallel machines: $m_{g}=10$ parallel machines in each stage $g=1,2 ; m_{g}=20$ parallel machines in each stage $g=3,4,5$; and $m_{g}=10$ parallel machines in stage $g=6$.

- for each assembly stage $g$ the available processing time $c_{g t}$ is the same in every period $t$ :

$$
c_{g t}=c_{g}=\varepsilon_{g} H m_{g} ; g=1, \ldots 6, t=1, \ldots, 14
$$

where parameter $\varepsilon_{g} \in(0,1)$ reflects the idle time of each machine waiting for the first production lot from upstream stages $1, \ldots, g-1$ and the idle time during processing of the last production lot at downstream stages $i+1, \ldots, f$, assuming that all production lots of each customer order are completed in a single period.

- Products

- 10 product types of three product groups, each to be processed on a separate group of machines (in the assembly stage 3 or 4 or 5 ),

- assembly times (in seconds) for product types:

$\begin{array}{rrrrrrr}\text { product type/stage } & 1 & 2 & 3 & 4 & 5 & 6 \\ 1 & 20 & 0 & 120 & 0 & 0 & 15 \\ 2 & 20 & 0 & 140 & 0 & 0 & 15 \\ 3 & 10 & 0 & 120 & 0 & 0 & 10\end{array}$




$\begin{array}{rrrrrrr}4 & 15 & 5 & 0 & 120 & 0 & 15 \\ 5 & 15 & 10 & 0 & 180 & 0 & 15 \\ 6 & 10 & 5 & 0 & 120 & 0 & 10 \\ 7 & 15 & 10 & 0 & 180 & 0 & 15 \\ 8 & 20 & 5 & 0 & 0 & 100 & 15 \\ 9 & 15 & 0 & 0 & 0 & 80 & 10 \\ 10 & 15 & 0 & 0 & 0 & 100 & 10\end{array}$

4. Customers: $n=521$ customer orders ranging from 5 to 8309 products, with various requested requested due dates, each to be completed in a single period. The total demand is 258414 products.

In the above example the set $L$ of product types is identical with the set $K$ of productspecific part types (i.e., $K=L=\{1, \ldots, 10\}$ ) and each product type $l$ requires one unit of the corresponding product-specific part type $k$ such that $k=l$, (i.e., $b_{k l}=1, k \in K, l \in L$ : $\left.k=l, b_{k l}=0, k \in K, l \in L: k \neq l\right)$, e.g. one printed wiring board of a specific design is required per one electronic device of the corresponding type. As a result, for each order $j \in J_{l}$ the required quantity of product-specific part type $k=l$ equals the quantity $o_{j}$ of the ordered products $l$.

Table 3. Computational results for the monolithic model INT: weighted-sum program $\mathbf{I N T}_{\lambda}$.

Table 4. Computational results for the monolithic model INT: lexicographic approach.

Table 5. Computational results for the hierarchical approach.

The characteristics of the (mixed) integer programs for the monolithic and for the hierarchical approach are summarized in Tables 3, 4 and in Table 5, respectively. The size of each program is represented by the total number of variables, Var., number of binary variables, Bin., number of integer variables, Int., number of constraints, Cons., and number of nonzero elements in the constraint matrix, Nonz. The counts presented in the tables are taken from the models after presolving. The last two columns of the tables present the solution values and CPU time in seconds required to find optimal solution and to prove its optimality or GAP\% if optimality is not proven within a specified CPU time limit. The computational experiments have been performed on a PC Pentium IV, 1.8GHz, RAM 1GB using AMPL/CPLEX 11 with a traditional branch and bound search and strong branching option. 
The solution results for the monolithic approach and the characteristics of weighted-sum mixed integer program $\mathbf{I N T} \mathbf{T}_{\lambda}$ for selected $\lambda$ and of the lexicographic mixed integer programs INT(1), INT(2) and INT(3) are summarized, respectively in Tables 3 and 4 . For the monolithic approach no proven optimal solution was determined in two hours limit of CPU time, and GAP was over $10 \%$ for the best solutions found. On the other hand, Table 4 indicates that proven optimal solution to INT(1) was found in less than one hour of CPU time, in two hours a feasible solution with GAP over $7 \%$ was determined for INT(2), however for INT(3) no feasible solution was reached within the CPU time limit. In Table 4 the solution value of each objective function for the lexicographic approach is presented along with the corresponding associated values of the remaining objective functions (in parentheses).

The solution results for the hierarchical approach and the characteristics of integer programs RCA, NDS and of mixed integer programs $\mathbf{S M D}(i)$ for $i \in I$ are summarized in Table 5 with different weight $\alpha$ applied in the objective function (63) of $\mathbf{S M D}(i)$.

While the monolithic approach is capable of finding non-dominated solution set of the integrated scheduling problem, the hierarchical approach was able to find the best solution with respect to the primary objective function $f_{1}$ - the number of tardy orders. On the other hand, the hierarchical approach leads to a greater total supply chain inventory holding cost $f_{2}$, because parts and products inventories are considered separately at two decision levels and, in addition, the cost of holding the inventory of parts is split among all subproblems of the base level. Unlike for the monolithic model, the computational effort required for the hierarchical approach is relatively small and proven optimal solutions have been reached in a short CPU time for each level problem. The coordinating constraints (30) and (66) have reduced CPU time up to $10 \%$.

Examples of the aggregated production schedule $\left(\sum_{j \in J} o_{j} z_{j t}, t \in T\right)$ for the producer and the aggregated manufacturing schedule $\left(\sum_{k \in K} u_{i k t}, t \in T^{(i)}\right)$ and the delivery schedule $\left(\sum_{k \in K} v_{i k t}, t \in T^{(i)}\right)$ for each supplier $i \in I$ are shown in Fig. 3 and Fig. 4, respectively for the monolithic model with the weighted-sum program and for the hierarchical approach.

Figure 3. Manufacturing, delivery and production schedules for the monolithic approach and the weighted-sum program $\mathbf{I N T}_{\lambda}$ with $\lambda_{1}=0.97, \lambda_{2}=0.02, \lambda_{3}=0.01$.

The results indicate that the shorter the transportation time from a supplier, the greater the total demand for parts of customer orders assigned to that supplier, and also the greater is the total number of production line start ups and the delivery of parts are more frequent and resemble more the just-in-time supplies. 
Figure 4. Manufacturing, delivery and production schedules for the hierarchical approach with $\alpha=0.5$ in (63).

Figure 5. Supply chain inventory.

Fig. 5 shows the supply chain inventory of parts manufactured by each supplier i.e., the sum of each supplier inventory of manufactured parts waiting for shipment or transported from the supplier to the producer or delivered to the producer and waiting for processing. In addition, the producer output inventory of finished products waiting for delivery to the customers and the total supply chain inventory of parts and finished products are presented.

Fig. 5 indicates that the hierarchical approach leads to greater stocks of parts, while both the approaches yield similar output inventory of the finished products. The total supply chain inventory of parts and products varies similarly over the planning horizon for both the approaches.

\section{Conclusion}

In this paper a hierarchical decision making framework has been proposed with a set of integer programming formulations and compared with a monolithic model for coordinated scheduling in a supply-production stage of a customer driven supply chain. The objective functions have integrated both the supply chain performance and the customer service level and in the problem considered the scheduling is combined with a selection of part supplier for each customer order and a due date setting for some orders. The hierarchical approach can be applied within a pull planning framework as it begins with due dates setting and suppliers selection for customer orders, then the orders assignment to planning periods over the horizon is determined for the producer, and finally the schedules for manufacturing and delivery of parts from each supplier to the producer are found.

The computational experiments modeled after a real-world integrated scheduling in a supply chain of high-tech products have indicated that the proposed hierarchical approach based on integer programming requires a relatively small CPU time to find the optimal solution for each level problem in a static case, where all order arrivals are known ahead of time. The last assumption can be relaxed, and the approach can also be used in a dynamic case where orders arrive irregularly over time. In this case, the scheduling decisions can be made upon 
arrival of each order or periodically upon arrivals of a number of orders in a specific time interval, given the set of already scheduled orders and the remaining available capacity.

The computational results have led to some observations on properties of the optimal schedules in the customer driven supply chain. For example:

- the shorter the transportation time from a supplier, the greater the total demand for parts of customer orders assigned to that supplier, and also the greater is the total number of production line start ups and the more frequent are the delivery of parts,

- the smaller the total number of tardy orders (the greater customer service level) achieved, the greater the total number of tardy products (i.e., a high customer service level can be achieved by delaying a few, large orders), and the greater the holding cost of the total supply chain inventory of parts and products,

- the smaller the total number of production line start-ups and part shipments, the greater the total supply chain inventory holding cost.

In the models proposed various simplifying assumptions have been introduced. For example, it has been assumed that each supplier is capable of manufacturing all the part types. In a more general setting, each supplier may only be prepared to manufacture a subset of part types and provide with the parts the corresponding subset of orders. In this case, supplier selection and supplier capacity constraints of INT and RCA should be modified appropriately. Furthermore, the proposed approaches can be enhanced to simultaneously consider the single- and the multi-period orders (see, Section 4.4). Finally, the two approaches can also be applied for different machine configurations of both the manufacturers of parts and the producer of finished products.

\section{Acknowledgments}

The author is grateful to two anonymous reviewers for providing constructive comments which helped to substantially improve this paper. This work has been partially supported by research grant of MNiSzW (N 519 03432/4143) and by AGH.

\section{References}

Alves, M.J., Climaco, J., A review of interactive methods for multiobjective integer and mixed-integer programming. European Journal of Operational Research, 2007, 180, 99-115.

Amaro, A.C.S. and Barbosa-Póvoa, A.P.F.D., Supply chain management with optimal scheduling. Industrial Engineering and Chemical Research, 2008, 47(1), 116-132. 
Chauhan, S.S., Gordon, V. and Proth, J.-M., Scheduling in supply chain environment. European Journal of Operational Research, 2007, 183(3), 961-970.

Chen, Z.-L., Integrated production and distribution operations: Taxonomy, models and review. D.Simchi-Levi, S.D.Wu and Z.-J.Shen, eds. Handbook of Quantitative Supply Chain Analysis: Modeling in the E-Business Era, 2004 (Kluwer Academic Publishers: Boston, MA).

Chen, Z.-L. and Vairaktarakis, G.L., Integrated scheduling of production and distribution operations, Management Science, 2005, 51, No.4, 614-628.

Chen, Z.-L. and Pundoor, G., Order assignment and scheduling in a supply chain, Operations Research, 2006, 54, No.3, 555-572.

Chen, Z.-L. and Hall, N.G., Supply chain scheduling: conflict and cooperation in assembly system, Operations Research, 2007, 55, No.6, 1072-1089.

Erenguc, S.S., Simpson and N.C., Vakharia, A.J., Integrated production/distribution planning in supply chains: an invited review, European Journal of Operational Research, 1999, 115, 219-236.

Goyal, S.K. and Deshmukh, S.G., Integrated procurement - production systems: a review, European Journal of Operational Research, 1992, 62(1), 1-10.

Goyal, S.K. and Deshmukh, S.G., Integrated procurement-production system in a just-intime environment - modeling and analysis, Production Planning and Control, 1997, 8(1), $31-36$.

Hall, N.G., Lesaoana, M. and Potts, C.N., Scheduling with fixed delivery dates, Operations Research, 2001, 49(1), 134-144.

Hall, N.G and Potts, C.N., Supply chain scheduling: Batching and delivery, Operations Research, 2003, 51(4), 566-584.

Kaczmarczyk, W., Sawik, T., Schaller, A. and Tirpak, T., Production planning and coordination in customer driven supply chains. Wybrane Zagadnienia Logistyki Stosowanej, Komitet Transportu PAN, 2006, no.3, 81-89.

Kolisch, R., Integration of assembly and fabrication for make-to-order production, International Journal of Production Economics, 2000, 68, 287-306.

Lee, W., A joint economic lot size model for raw material ordering, manufacturing setup, and finished goods delivering, Omega, 2005, 33, 163-174.

Moon, C., Lee, Y.H., Jeong, C.S. and Yun, J.S., Integrated process planning and scheduling in a supply chain, Computers and Industrial Engineering, 2007, available on line. 
Pochet, Y. and Wolsey, L.A., Production Planning by Mixed Integer Programming, 2006 (Springer: New York).

Sawik, T., Monolithic vs. hierarchical balancing and scheduling of a flexible assembly line. European Journal of Operational Research, 2002, 143(1), 115-124.

Sawik, T., Hierarchical approach to production scheduling in make-to-order assembly, International Journal of Production Research, 2006, 44(4), 801-830.

Sawik, T., A lexicographic approach to bi-objective scheduling of single-period orders in make-to-order manufacturing. European Journal of Operational Research, 2007a, 180(3), 1060-1075.

Sawik, T., Multi-objective master production scheduling in make-to-order manufacturing, International Journal of Production Research, 2007b, 45(12), 2629-2653.

Sawik, T., A multi-objective customer orders assignment and resource leveling in make-toorder manufacturing. International Transactions in Operational Research, 2007c, 14(6), 491-508.

Schneeweiss, Ch. and Zimmer,K., Hierarchical coordination mechanism within the supply chain. European Journal of Operational Research, 2004, 154, 687-703.

Shapiro, J.F., Modeling the Supply Chain, 2001 (Duxbury: Pacific Grove, CA).

Steuer, R.E., Multiple Criteria Optimization: Theory, Computation and Application, 1986 (Wiley: New York).

Thomas, D.J., Griffin, P.M., 1996. Coordinated supply chain management, European Journal of Operational Research, 94(1), 1-15. 


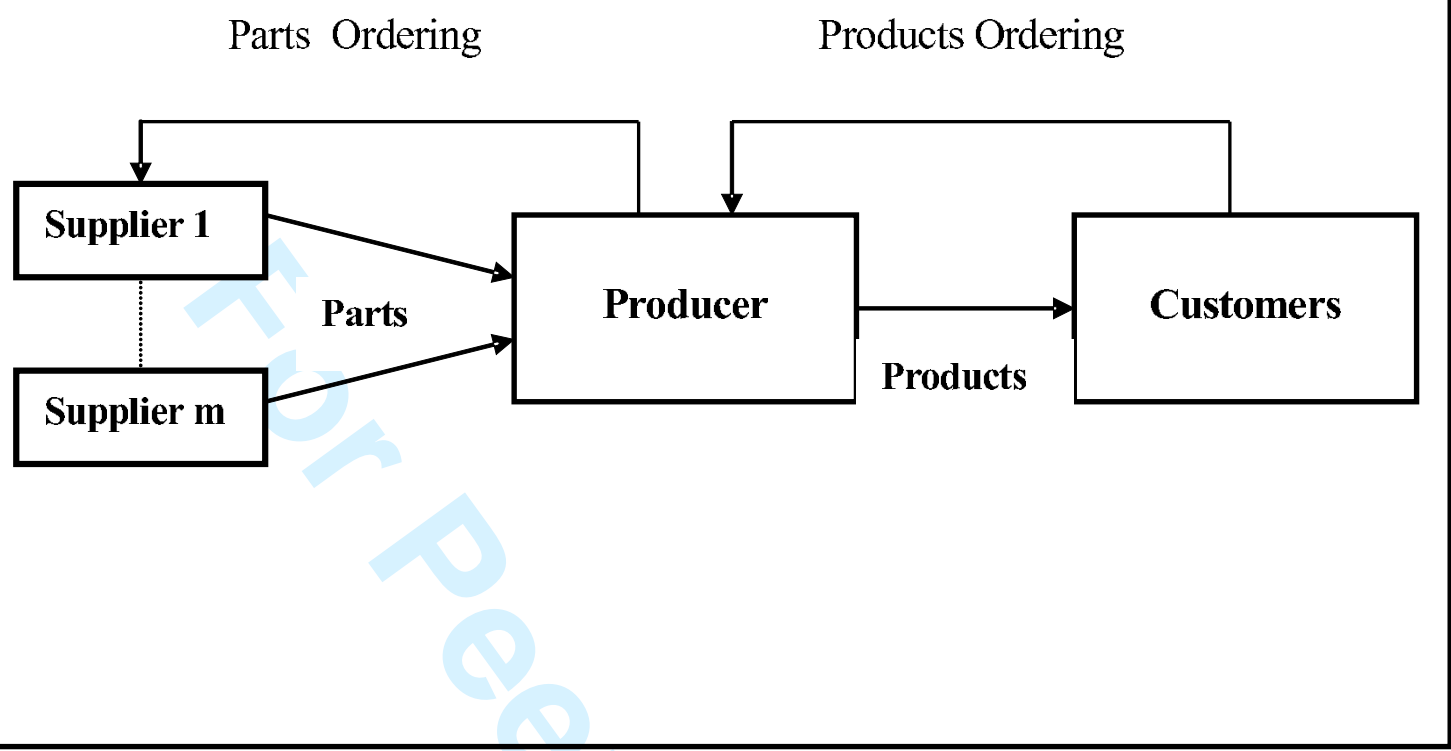

Figure 1. Customer driven supply chain.

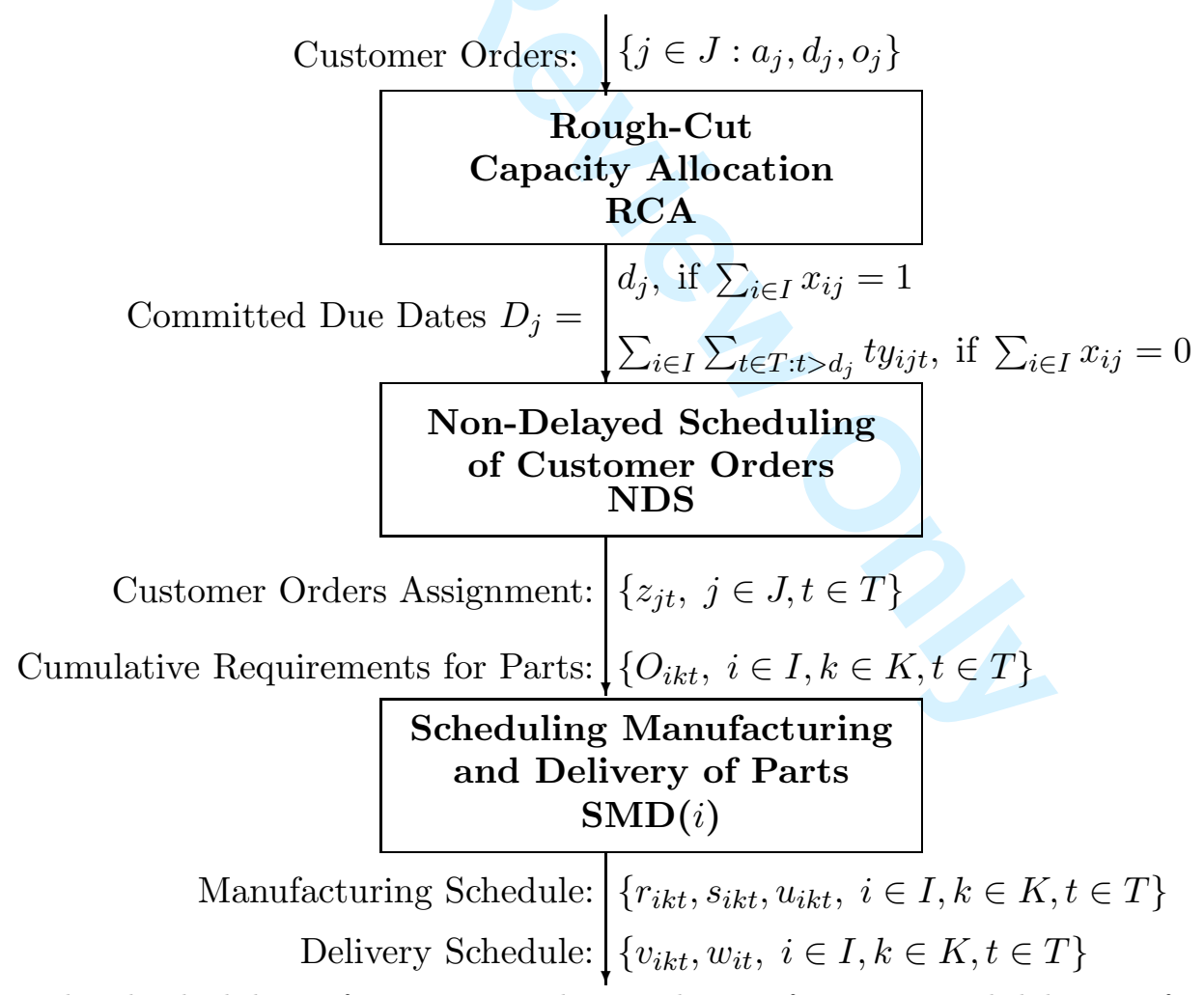

Figure 2. Hierarchical scheduling of customer orders and manufacturing and delivery of parts. 
Table 1. Notation: indices and parameters

\begin{tabular}{|c|c|c|}
\hline \multicolumn{3}{|r|}{ Indices } \\
\hline$g$ & $=$ & assembly stage, $g \in G=\{1, \ldots, f\}$ \\
\hline$i$ & $=$ & supplier, $i \in I=\{1, \ldots, m\}$ \\
\hline$j$ & $=$ & customer order, $j \in J=\{1, \ldots, n\}$ \\
\hline$k$ & $=$ & part type $k \in K$ \\
\hline$l$ & $=$ & product type, $l \in L$ \\
\hline$t$ & $=$ & planning period, $t \in T=\{1, \ldots, h\}$ \\
\hline & & Input Parameters \\
\hline$a_{j}, d_{j}, D_{j}, o_{j}$ & $=$ & $\begin{array}{l}\text { ready date, customer requested due date, committed due date, size } \\
\text { of order } j\end{array}$ \\
\hline$b_{k l}$ & $=$ & unit requirement of product type $l$ for part type $k$ \\
\hline$c_{g t}$ & $=$ & capacity of each machine in assembly stage $g$ in period $t$ \\
\hline$C_{g}(t, d)$ & $=$ & $\begin{array}{l}m_{g} \sum_{\tau \in T: t \leq \tau \leq d} c_{g \tau} \text { - cumulative capacity available in assembly stage } \\
g \text { in periods } t \text { through } d\end{array}$ \\
\hline$c^{i}(t)$ & $=$ & manufacturing and delivery capacity of supplier $i$ in period $t$ \\
\hline$C^{i}(d)$ & $=$ & $\begin{array}{l}\sum_{t \in T: t \leq d} c^{i}(t) \text { - cumulative manufacturing and delivery capacity of } \\
\text { supplier } i \text { until period } d\end{array}$ \\
\hline$e_{i}$ & $=$ & the earliness of manufacturing start time for supplier $i$ \\
\hline$H$ & $=$ & length of each planning period \\
\hline$J_{l}$ & $=$ & the subset of orders for product type $l$ \\
\hline$M_{i}$ & $=$ & number of parallel production lines at supplier $i$ \\
\hline$m_{g}$ & $=$ & number of parallel machines in assembly stage $g$ \\
\hline$p_{g j}$ & $=$ & processing time in assembly stage $g$ of each product in order $j$ \\
\hline$q_{i k}$ & $=$ & processing time for one unit of part type $k$ at supplier $i$ \\
\hline$\underline{V}, \bar{V}$ & $=$ & the minimum, maximum shipment capacity, respectively \\
\hline$T^{(i)}$ & $=$ & $\left\{-e_{i}, \ldots,-1,1, \ldots, h\right\}-$ enlarged, ordered set of planning periods \\
\hline$\pi_{g j}$ & $=$ & $\begin{array}{l}\left\lfloor c_{g} / p_{g j}\right\rfloor \text { the one machine-period production rate at assembly stage } g \\
\text { for products in order } j\end{array}$ \\
\hline$\rho_{i k}$ & $=$ & $\begin{array}{l}\left\lfloor\left(H-\sigma_{i}\right) / q_{i k}\right\rfloor \text { the one machine-period worst case production rate of } \\
\text { part type } k \text { at supplier } i\end{array}$ \\
\hline$\sigma_{i}$ & $=$ & the start-up time of each production line at supplier $i$ \\
\hline$\theta_{i}$ & $=$ & the delivery time from supplier $i$ to producer \\
\hline$\varphi_{1 i k}, \varphi_{2 i k}, \varphi_{3 k}, \varphi_{4 j}$ & $=$ & $\begin{array}{l}\text { inventory holding cost per unit of part stored by supplier, trans- } \\
\text { ported to producer, stored by producer, per unit of finished prod- } \\
\text { uct stored by producer, respectively }\end{array}$ \\
\hline$\psi_{1 i k}, \psi_{2 i}$ & $=$ & unit cost of production line start-up, part shipment, respectively \\
\hline
\end{tabular}


Table 2. Notation: decision variables

\begin{tabular}{|c|c|c|}
\hline \multicolumn{3}{|r|}{ Model INT } \\
\hline$r_{i k t}$ & $=$ & $\begin{array}{l}\text { number of parallel production lines of supplier } i \text { setup for manufac- } \\
\text { turing part type } k \text { in period } t \text { (production line setup variable) }\end{array}$ \\
\hline$s_{i k t}$ & $=$ & $\begin{array}{l}\text { number of parallel production lines of supplier } i \text { started up in pe- } \\
\text { riod } t \text { to manufacture part type } k \text { after processing another part type } \\
\text { (production line start-up variable) }\end{array}$ \\
\hline$u_{i k t}$ & $=$ & $\begin{array}{l}\text { manufacturing lot at supplier } i \text { of part type } k \text { in period } t \text { (manufac- } \\
\text { turing lot variable) }\end{array}$ \\
\hline$v_{i k t}$ & $=$ & $\begin{array}{l}\text { delivery lot from supplier } i \text { of part type } k \text { in period } t \text { (delivery lot } \\
\text { variable) }\end{array}$ \\
\hline$w_{i t}$ & $=$ & $\begin{array}{l}1 \text {, if delivery of parts from supplier } i \text { is scheduled for period } t \text {, other- } \\
\text { wise } w_{i t}=0 \text { (delivery timing variable) }\end{array}$ \\
\hline$\zeta_{i j t}$ & $=$ & $\begin{array}{l}1 \text {, if customer order } j \text { is supplied with parts by supplier } i \text { and as- } \\
\text { signed for processing to planning period } t \text {; otherwise } \zeta_{i j t}=0 \text { (order } \\
\text { assignment and supplier selection variable) }\end{array}$ \\
\hline \multicolumn{3}{|r|}{ Model RCA } \\
\hline$x_{i j}$ & $=$ & $\begin{array}{l}1 \text {, if order } j \text { is accepted with its customer requested due date and } \\
\text { selected for supplier } i ; x_{i j}=0 \text { if order } j \text { needs delaying to be accepted } \\
\text { (order acceptance and supplier selection variable) }\end{array}$ \\
\hline$y_{i j t}$ & $=$ & $\begin{array}{l}1 \text {, if delayed order } j \text { is selected for supplier } i \text { and is assigned the } \\
\text { adjusted due date } t,\left(t>d_{j}\right) \text {; otherwise } y_{i j t}=0 \text { (due date setting } \\
\text { and supplier selection variable) }\end{array}$ \\
\hline \multicolumn{3}{|r|}{ Model NDS } \\
\hline$z_{j t}$ & $=$ & $\begin{array}{l}1 \text {, if customer order } j \text { is assigned to planning period } t \text {; otherwise } \\
z_{j t}=0 \text { (order assignment variable) }\end{array}$ \\
\hline
\end{tabular}


Table 3. Computational results for the monolithic model INT: weighted-sum program $\mathbf{I N T}_{\lambda}$

\begin{tabular}{|l|c|c|c|c|c||c|c|}
\hline$\lambda_{1}, \lambda_{2}, \lambda_{3}$ & Var. & Bin. & Int. & Cons. & Nonz. & $f_{1}, f_{2}, f_{3}$ & GAP\% $^{(a)}$ \\
\hline $0.97,0.02,0.01$ & 23262 & 21402 & 960 & 4384 & 500446 & $2,793,119$ & 11.08 \\
$0.75,0.15,0.1$ & 23262 & 21402 & 960 & 4384 & 500446 & $7,774,101$, & 12.09 \\
$0.7,0.2,0.1$ & 23262 & 21402 & 960 & 4384 & 500446 & $10,765,114$ & 12.37 \\
$0.6,0.3,0.1$ & 23262 & 21402 & 960 & 4384 & 500446 & $13,738,104$ & 9.22 \\
$0.5,0.3,0.2$ & 23262 & 21402 & 960 & 4384 & 500446 & $17,741,92$ & 11.87 \\
$0.4,0.35,0.25$ & 23262 & 21402 & 960 & 4384 & 500446 & $24,735,108$ & 13.47 \\
\hline
\end{tabular}

(a) GAP\% for 7200 CPU seconds on a PC Pentium IV, 1.8GHz, RAM 1GB, CPLEX 11.

Table 4. Computational results for the monolithic model INT: lexicographic approach

\begin{tabular}{|l|c|c|c|c|c||c|c|}
\hline Model & Var. & Bin. & Int. & Cons. & Nonz. & Solution value & CPU(GAP\% $)^{(a)}$ \\
\hline $\operatorname{INT}(1)$ & 23262 & 21402 & 960 & 4384 & 500446 & $f_{1}=1,\left(f_{2}=1739, f_{3}=231\right)$ & 933 \\
$\operatorname{INT}(2)$ & 23262 & 21402 & 960 & 4385 & 510658 & $f_{2}=836,\left(f_{1}=1, f_{3}=160\right)$ & $(7.16 \%)$ \\
$\operatorname{INT}(3)$ & 23262 & 21402 & 960 & 4386 & 532656 & $f_{3}=?$ & $(b)$ \\
\hline
\end{tabular}

(a) CPU seconds for proving optimality on a PC Pentium IV, 1.8GHz, RAM 1GB/CPLEX 11 or GAP\% if optimality not proven in 7200 CPU seconds.

(b) no feasible solution found within $7200 \mathrm{CPU}$ seconds. 
Table 5. Computational results for the hierarchical approach

\begin{tabular}{|c|c|c|c|c|c|c|c|}
\hline Model & Var. & Bin. & Int. & Cons. & Nonz. & Solution values & $\mathrm{CPU}^{(a)}$ \\
\hline $\mathrm{RCA}$ & 12255 & 11775 & 480 & 1837 & 1332549 & $f_{1}=1$ & 30 \\
\hline NDS & 3939 & 3539 & 400 & 1004 & 49884 & $f_{20}=209$ & 2320 \\
\hline \multicolumn{8}{|c|}{$\alpha=0.05$ in $(63)$} \\
\hline $\operatorname{SMD}(1)$ & 645 & 15 & 320 & 1291 & 9944 & $f_{21}=283, f_{31}=24$ & 1210 \\
\hline $\operatorname{SMD}(2)$ & 592 & 11 & 299 & 1141 & 7902 & $f_{22}=321, f_{32}=33$ & 96 \\
\hline $\operatorname{SMD}(3)$ & 621 & 11 & 320 & 1175 & 7959 & $f_{23}=432, f_{33}=38$ & 57 \\
\hline \multicolumn{8}{|c|}{$f_{2}=f_{20}+\sum_{i \in I} f_{2 i}=1245, f_{3}=\sum_{i \in I} f_{3 i}=95$} \\
\hline \multicolumn{8}{|c|}{$\alpha=0.25$ in $(63)$} \\
\hline $\operatorname{SMD}(1)$ & 645 & 15 & 320 & 1291 & 9944 & $f_{21}=204, f_{31}=33$ & 548 \\
\hline $\operatorname{SMD}(2)$ & 592 & 11 & 299 & 1141 & 7902 & $f_{22}=261, f_{32}=41$ & 11 \\
\hline $\operatorname{SMD}(3)$ & 621 & 11 & 320 & 1175 & 7959 & $f_{23}=353, f_{33}=50$ & 45 \\
\hline \multicolumn{8}{|c|}{$f_{2}=f_{20}+\sum_{i \in I} f_{2 i}=1027, f_{3}=\sum_{i \in I} f_{3 i}=124$} \\
\hline \multicolumn{8}{|c|}{$\alpha=0.5$ in $(63)$} \\
\hline $\operatorname{SMD}(1)$ & 645 & 15 & 320 & 1291 & 9944 & $f_{21}=179, f_{31}=47$ & 562 \\
\hline $\operatorname{SMD}(2)$ & 592 & 11 & 299 & 1141 & 7902 & $f_{22}=255, f_{32}=45$ & 8 \\
\hline $\operatorname{SMD}(3)$ & 621 & 11 & 320 & 1175 & 7959 & $f_{23}=343, f_{33}=56$ & 6 \\
\hline \multicolumn{8}{|c|}{$f_{2}=f_{20}+\sum_{i \in I} f_{2 i}=986, f_{3}=\sum_{i \in I} f_{3 i}=148$} \\
\hline \multicolumn{8}{|c|}{$\alpha=0.75$ in $(63)$} \\
\hline $\operatorname{SMD}(1)$ & 645 & 15 & 320 & 1291 & 9944 & $f_{21}=175, f_{31}=52$ & 73 \\
\hline $\operatorname{SMD}(2)$ & 592 & 11 & 299 & 1141 & 7902 & $f_{22}=252, f_{32}=49$ & 11 \\
\hline $\operatorname{SMD}(3)$ & 621 & 11 & 320 & 1175 & 7959 & $f_{23}=341, f_{33}=58$ & 3 \\
\hline \multicolumn{8}{|c|}{$f_{2}=f_{20}+\sum_{i \in I} f_{2 i}=977, f_{3}=\sum_{i \in I} f_{3 i}=159$} \\
\hline \multicolumn{8}{|c|}{$\alpha=0.95$ in $(63)$} \\
\hline $\operatorname{SMD}(1)$ & 645 & 15 & 320 & 1291 & 9944 & $f_{21}=175, f_{31}=60$ & 487 \\
\hline $\operatorname{SMD}(2)$ & 592 & 11 & 299 & 1141 & 7902 & $f_{22}=250, f_{32}=56$ & 21 \\
\hline $\operatorname{SMD}(3)$ & 621 & 11 & 320 & 1175 & 7959 & $f_{23}=341, f_{33}=64$ & 56 \\
\hline \multicolumn{8}{|c|}{$f_{2}=f_{20}+\sum_{i \in I} f_{2 i}=975, f_{3}=\sum_{i \in I} f_{3 i}=180$} \\
\hline
\end{tabular}

${ }^{(a)}$ CPU seconds for proving optimality on a PC Pentium IV, 1.8GHz, RAM 1GB /CPLEX 11. 

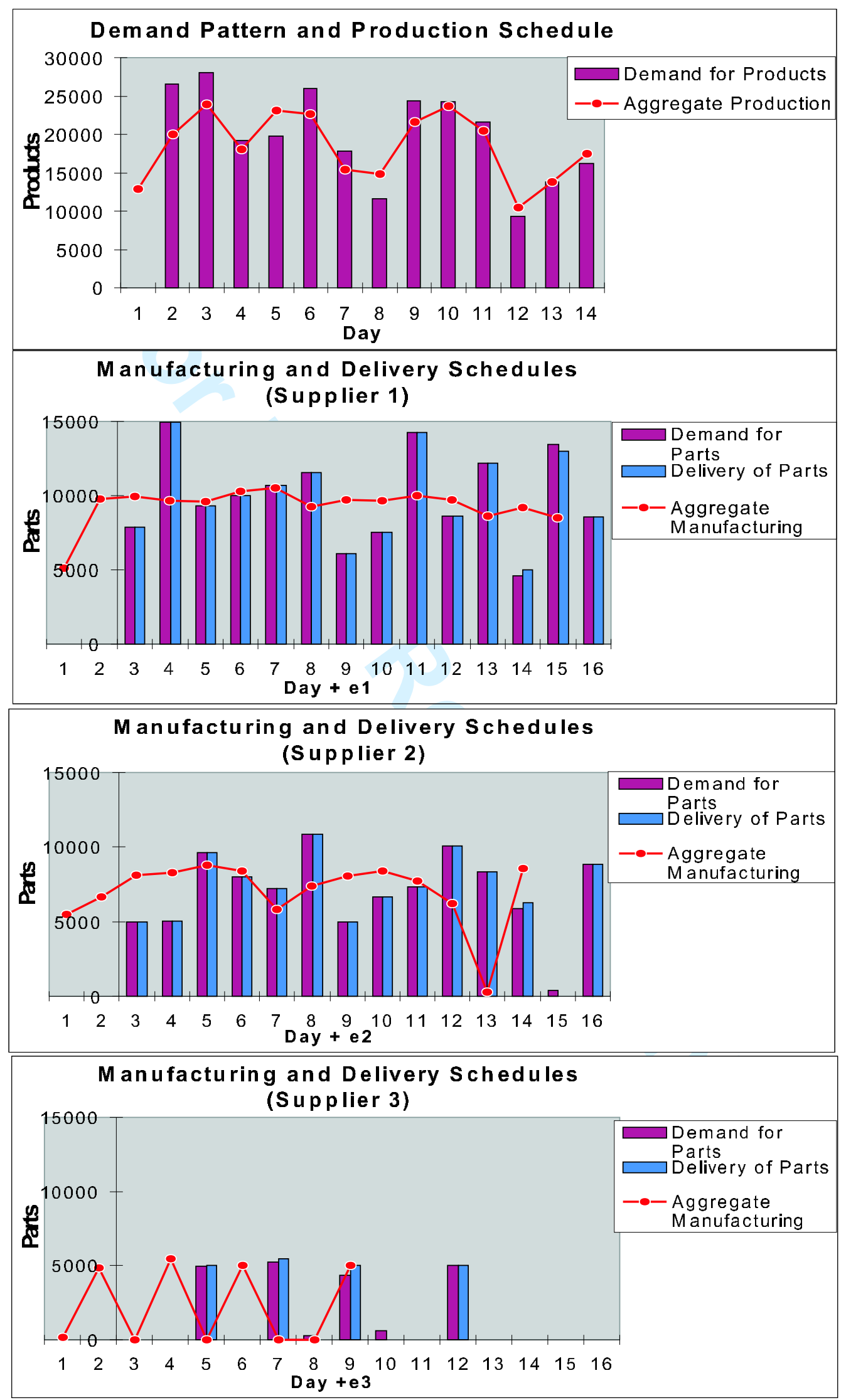

Figure 3. Manufacturing, delivery and production schedules for the monolithic approach and

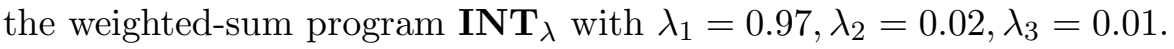



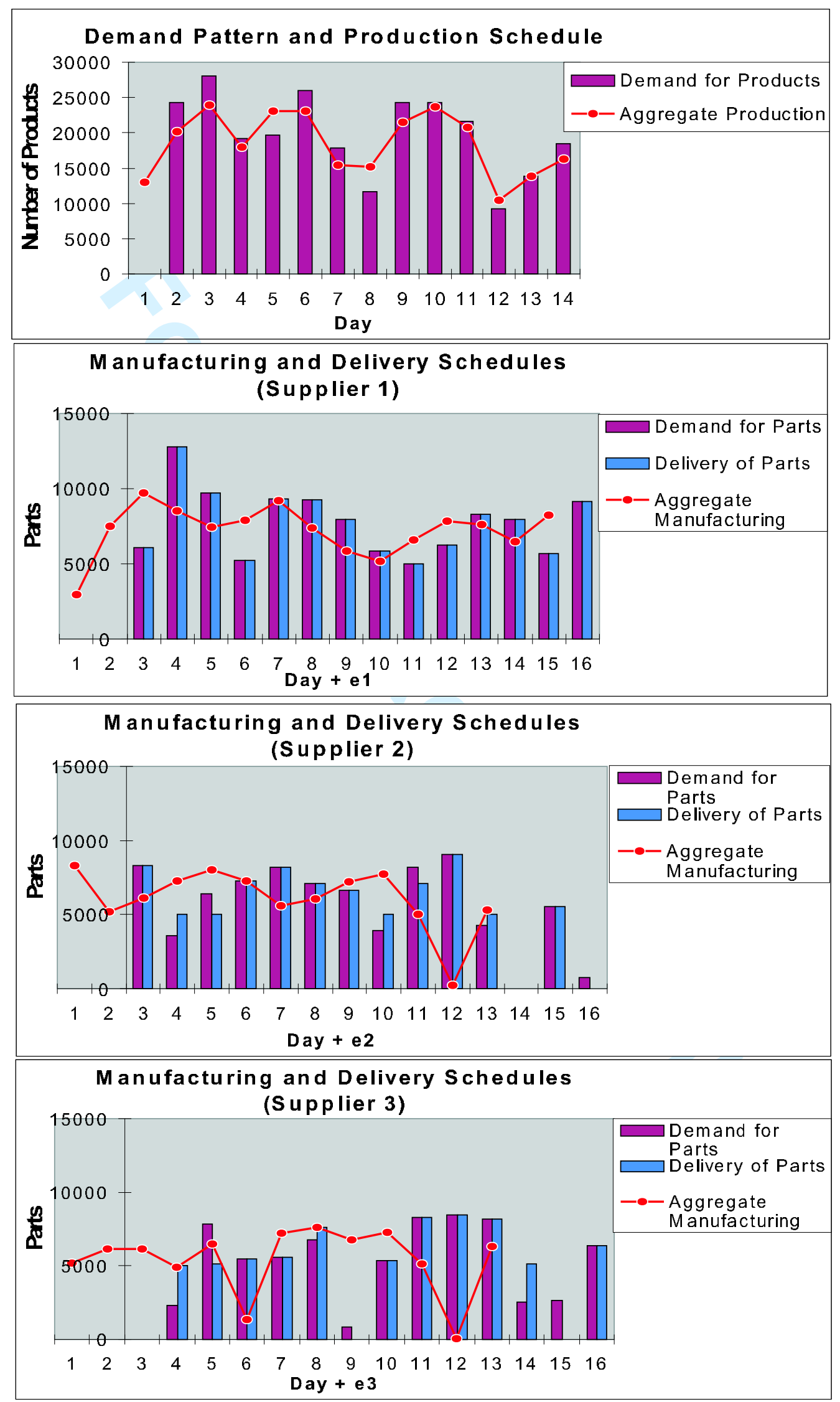

Figure 4. Manufacturing, delivery and production schedules for the hierarchical approach with $\alpha=0.5$ in (63). 

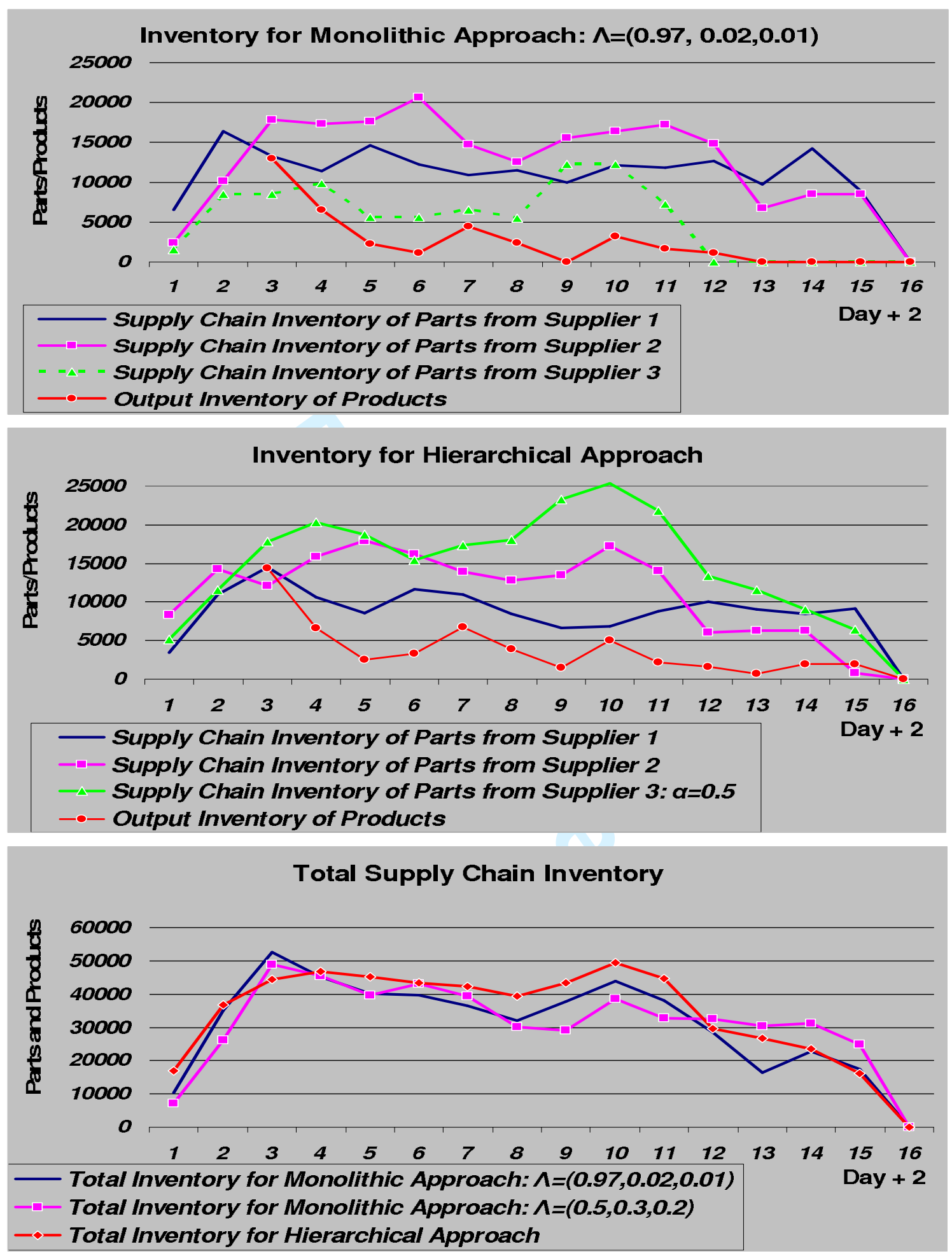

Figure 5. Supply chain inventory. 